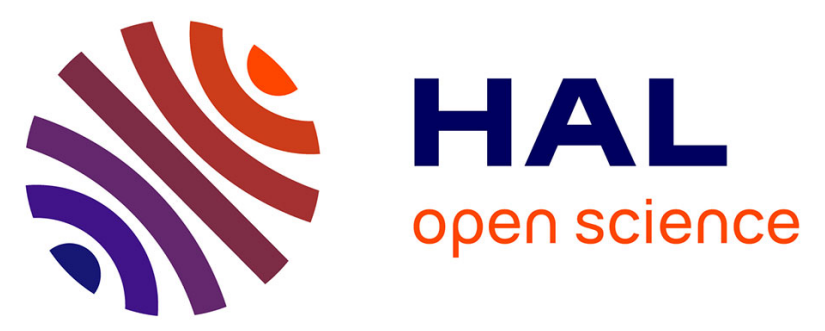

\title{
Enterocytic differentiation is modulated by lipid rafts-dependent assembly of adherens junctions.
}

Nicolas T. Chartier, Michèle G. Lainé, Benjamin Ducarouge, Christiane

Oddou, Bruno Bonaz, Corinne Albiges-Rizo, Muriel R. Jacquier-Sarlin

\section{- To cite this version:}

Nicolas T. Chartier, Michèle G. Lainé, Benjamin Ducarouge, Christiane Oddou, Bruno Bonaz, et al.. Enterocytic differentiation is modulated by lipid rafts-dependent assembly of adherens junctions.: lipid raft and enterocytic differentiation. Experimental Cell Research, 2011, 317 (10), pp.1422-36. 10.1016/j.yexcr.2011.03.009 . inserm-00668336

\section{HAL Id: inserm-00668336 https://www.hal.inserm.fr/inserm-00668336}

Submitted on 9 Feb 2012

HAL is a multi-disciplinary open access archive for the deposit and dissemination of scientific research documents, whether they are published or not. The documents may come from teaching and research institutions in France or abroad, or from public or private research centers.
L'archive ouverte pluridisciplinaire HAL, est destinée au dépôt et à la diffusion de documents scientifiques de niveau recherche, publiés ou non, émanant des établissements d'enseignement et de recherche français ou étrangers, des laboratoires publics ou privés. 


\section{Enterocytic differentiation is modulated by lipid rafts-dependent assembly of adherens junctions}

Nicolas T. Chartier ${ }^{1,2,5 *}$, Michèle G. Lainé ${ }^{1,2,4 *}$, Benjamin Ducarouge, ${ }^{1,2}$, Christiane Oddou ${ }^{1,3}$, Bruno Bonaz ${ }^{2,4}$, Corinne Albiges-Rizo ${ }^{1,2,3}$ and Muriel R. Jacquier-Sarlin ${ }^{1,2,4 \dagger}$

From : 1 : Centre de Recherche Inserm U823, Institut Albert Bonniot. Equipe de la Dynamique des Systèmes d'Adhérence et de la Différenciation, Site Santé BP 170 La Tronche F-38042 Grenoble Cedex 9, France ; 2 : Université Joseph Fourier, F-38000 Grenoble, France ; 3 : Centre National de la Recherche Scientifique, Equipe de Recherche Labellisée 3148.

Present address: 4 : Centre de Recherche Inserm U836, Grenoble Institut des Neurosciences. Equipe du Stress et des Interactions Neurodigestives, Site Santé BP 170 La Tronche F-38042 Grenoble Cedex 9, France ; 5 : Institut de Recherche en Immunologie et en Cancérologie, Unité de recherche en division et différenciation cellulaire, Université de Montréal, CP 6128, Succ. Centre-Ville, Montreal, QC, H3C $3 J 7$ Canada.

* These authors contributed equally to this work

${ }^{\dagger}$ To whom correspondence should be addressed: Centre de Recherche Inserm U836, Grenoble Institut des Neurosciences. Equipe du Stress et des Interactions Neurodigestives, Site Santé BP 170 La Tronche F-38042 Grenoble Cedex 9, France. Tel.: (+33) 476-56-52-50; Fax: (+33) 476-56-05-54;

E-mail: jacquier-sarlin@ujf-grenoble.fr

Running title: lipid raft and enterocytic differentiation

Author involved with the manuscript: Lainé, Chartier and Ducarouge: acquisition of data; analysis and interpretation of data; statistical analysis and drafting of the manuscript; Oddou: technical assistance; Bonaz and Albiges-Rizo: critical revision of the manuscript and obtained funding; Jacquier-sarlin: study concept and design, drafting of the manuscript and study supervision.

Conflicts of interest: The authors disclose no conflicts.

Abbreviations used: AJ, adherens junctions; LR, lipid raft; CTx, cholera Toxin; ALP, alkaline phosphatase; DPPIV, dipeptidyl IV; shRNA, short hairpin RNA. 


\begin{abstract}
Integrity of the epithelial barrier is determined by apical junctional complexes which also participate in the signalling pathways inducing intestinal cell differentiation. Lipid rafts (LR) have been proposed to play a role in the organization and the function of these intercellular complexes. This study investigated potential mechanisms by which LR could participate in the establishment of adherens junctions ( $\mathrm{AJ})$ and the initiation of enterocytic differentiation. We showed that the differentiation of epithelial cells in rat colons correlates with the emergence of LR. Using HT-29 cells we demonstrated that during the differentiation process, LR are required for the recruitment and the association of p120ctn to E-cadherin. Silencing of flotillin-1, a LR component, alters the recruitment of AJ proteins in LR and delays the expression of differentiation markers. Furthermore, the ability of p120ctn/E-cadherin complexes to support cell differentiation is altered in HT-29 Rac1N17 cells. These results show a contributory role of LR in the enterocytic differentiation process, which serve as signalling platforms for Rac1-mediated organization of AJ. A better understanding of the mechanism involved in the establishment of junctional complex and their role in enterocytic differentiation provides new insights into the regulation of intestinal homeostasis.
\end{abstract}

Keywords: Rac1, adherens junctions; lipid rafts; flotillin; intestinal cell differentiation. 


\section{Introduction}

The digestive and protective functions of the intestinal mucosa depend on constant renewal and differentiation of the epithelium which forms a barrier of polarized cells joined by a complex set of cell-cell junctions. Adhesive interactions between cells are key determinants of normal tissue organisation during development and restitution but also in diseases. Increased permeability of the intestinal epithelium is responsible for the physiopathology of a variety of gastrointestinal disorders [1]. Cadherins are transmembrane adhesion receptors that mediate calcium-dependent cell-cell adhesion within adherens junctions (AJ) through homodimerization of their extracellular domains [2]. Catenins, the proteins interacting with the cytoplasmic domain of cadherin, couple cadherin either directly or indirectly to the cortical cytoskeleton [3]. Cadherin clustering and the anchorage to the cortical cytoskeleton transform the weak adhesive bonds into a mature AJ. This dynamic equilibrium is important for tissue morphogenesis or wound healing, when epithelial cells need to become motile [4].

Adhesion complexes are also preferential sites for signal transduction controlling the cell state, proliferation and differentiation [5-7]. Several mechanisms have been implicated in the regulation of cadherin-mediated adhesiveness including association of their cytoplasmic domain with catenins, the phosphorylation status of catenin/cadherin complexes and clustering of cadherins at the cell membrane (reviewed in [2]). Accumulating evidences indicate a role for p120ctn in the regulation of cell adhesiveness in epithelial cells, by regulating cadherin stability and turnover (reviewed in [8]). We and others have shown that Ecadherin binding to p120ctn at the plasma membrane ensures local strengthening and maturation of AJ [9-11]. Overexpression studies demonstrated that cytoplasmic proteins, such as the Rho family small GTPases, are another partners by which p120ctn might regulate cadherin-dependent adhesion (reviewed in [12]). Rho GTPases are well known for their 
pleiotropic activities on the actin cytoskeleton, vesicular trafficking, protein phosphorylation and gene transcription[13]. Members of these GTP-binding proteins have also emerged as key mediators of cadherin functions (reviewd by $[14,15]$ ). Nevertheless, the involvement of each Rho GTPases in cell-cell adhesion differs, depending on the cellular context and the maturation status of the junction [16-18]. It was proposed that p120ctn, a member of the Armadillo repeat family of catenins, could act by differentially recruiting and activating small GTPases at the site of cell-cell adherens but the timing and the way these proteins are corecruited is still unclear.

In epithelial cells, assembly of adhesion complexes occurs at the plasma membrane, where individual proteins and lipids are known to be restricted to apical and basolateral domains. Specialized subdomains that are highly enriched in cholesterol and sphingolipids, referred to lipid raft (LR) microdomains are involved in the biogenesis of apical membrane (reviewed by [19]). LR are also enriched in key signalling molecules suggesting that they could function as organizing centers for signalling [20, 21]. Indeed, these microdomains have been proposed to play a role in the spatial organization and function of tight junctions [22], and later, in the regulation of $\mathrm{N}$-cadherin function [23]. The physiological context of intestinal epithelium which is in constant renewal, may place constraints on how LR can be organized and therefore, on how they participate in AJ mediated-cell differentiation. The flotillin protein family consists of two ubiquitously expressed isoforms, flotillin-1 and flotillin-2, that are evolutionary highly conserved. They have been linked to many cellular events and in particular, cellular traffic [24-26]. While they have been described to be expressed in LR, the subcellular localization of flotillins is highly dynamic: flotillins externalize from intracellular compartments to the plasma membrane during the process of cellular differentiation [27] and their traffic is down-regulated upon establishment of cell-cell contact or cytoskeleton disruption, suggesting a role for flotillin in the regulation of AJ assembly and/or maturation 
[28]. Here we show that E-cadherin and p120ctn interact preferentially in LR at the site of cell-cell contacts and that the disruption of LR impairs the formation of this complex. Using shRNA or dominant negative form of Rac1, we show that flotillin-1 as well as Rac1 activity are both necessary for the recruitment of p120ctn and the formation of E-cadherin-p120ctn complexes in LR. This signaling pathway is required for the enterocytic differentiation of HT29 cells. Our results unravel the complex relationship between p120ctn, Rho-GTPases and cadherin, and identify a new function for flotillin-1 in LR-mediated maturation of AJ and intestinal cell differentiation.

\section{Materials and methods}

\section{Cell culture and animals}

The human colon adenocarcinoma HT-29 cell line was used as an in vitro model of intestinal epithelial cells. They were routinely cultured at $37^{\circ} \mathrm{C}$ in a $5 \% \mathrm{CO}_{2}$ atmosphere in Dulbecco Minimal Essential Medium (DMEM) containing $25 \mathrm{mM}$ glucose (Invitrogen, Cergy Pontoise, France) and supplemented with $10 \%$ foetal calf serum, penicillin and streptomycin (standard medium). The medium was changed every day to avoid glucose exhaustion, which leads to differentiation. The differentiation of HT-29 cells was initiated by replacing the standard medium for glucose free DMEM supplemented with $10 \%$ dialyzed foetal calf serum, $5 \mathrm{mM}$ galactose, $15 \mathrm{mM}$ HEPES, penicillin, and streptomycin. This medium (Gal-medium or differentiating medium) was changed every day. Male Spague Dawley rats, 250-300g, were purchased from Charles River France and housed in a temperature-controlled environment for 1 week. They were sacrificed in agreement with local ethic committee policies, by $40 \mathrm{mg} / \mathrm{kg}$ IP injection of pentobarbital and submitted to $200 \mathrm{~mL}$ intra-cardiac perfusion of $\mathrm{NaCl} 0,9 \%$. 


\section{Antibodies and reagents}

Anti-villin was kindly provided by Dr. Louvard (Institute Curie, Paris, France). Anti-human Ecadherin monoclonal antibody (HECD1) was purchased from Takara Biochemicals (Shiga, Japan). Anti-Rac1 monoclonal antibody was obtained from Upstate Biotechnology. Monoclonal antibodies against flotillin-1, p120ctn (clone 98), green fluorescent protein (GFP) and $\mathrm{p} 27^{\mathrm{Kip} 1}$ (clone 57) were purchased from BD Biosciences (Pont de Claix, France). Rabbit polyclonal anti-p120ctn and anti-RhoA were from Santa Cruz Biotechnology (Tebu-Bio, Le Perray en Yvelines, France). Polyclonal antibody against actin, Fluorescein IsoThioCyanate conjugated Cholera Toxin B subunit (FITC-CTx) and methyl- $\beta$ cyclo dextrin were purchased from Sigma-Aldrich (L'isle d'Abeau, France).Goat anti-IgG2a, (Immunotech, Marseille, France) was used as control in immunoprecipitation experiments. Secondary antibodies used were antibodies coupled to Alexa 546 (Molecular Probes, Eugene, Origan, USA) and to Horseradish peroxidase (Biorad, Hercules, CA). Phosphatase and protease inhibitor cocktails, and amphotericin B were purchased from Calbiochem (Montluçon, France) and cholesterol oxidase was from Roche (Meylan, Fance).

\section{Retrovirus production and infection}

shRNA oligonucleotides targeting GFP, human p120ctn and flotillin-1 cloned into pSM2c vectors were purchased from Openbiosystems (Huntsville, Alabama, USA). The Rac1N17 construct encoding the dominant-negative form of Rac1 GTPase was cloned into the pBabe retroviral expression vector. Amphotropic retrovirus stocks were obtained by Exgen (Euromedex, Souffelweyersheim, France) mediated transient transfection of the retroviral vector DNAs into Phoenix packaging cells. Target HT-29 cells were infected in the presence of $4 \mu \mathrm{g} / \mathrm{ml}$ polybrene (Sigma-Aldrich) then cultured in medium containing $2 \mu \mathrm{g} / \mathrm{ml}$ puromycin 
(BD Biosciences) to select virus-infected cells. Following selection, cells were pooled, expanded, and tested for protein expression by western blotting.

\section{Isolation of lipid rafts}

Briefly, postnuclear supernatant from $5 \times 10^{7}$ HT-29 cells was solubilised in $1.5 \mathrm{ml}$ of buffer A (25 mM HEPES pH 7.4, $150 \mathrm{mM} \mathrm{NaCl}, 5 \mathrm{mM}$ EGTA, protease inhibitors mixture) containing $1 \%$ Triton $\mathrm{X} 100$ for $1 \mathrm{~h}$ at $4^{\circ} \mathrm{C}$. Lysates were ultracentrifuged after mixing with an equal volume of $80 \%$ sucrose in buffer $\mathrm{A}$ and laid down at the bottom of a ultracentrifuge tube, which was then overlaid with $6 \mathrm{~mL}$ of $38 \%$ sucrose followed by $3 \mathrm{~mL}$ of $5 \%$ sucrose, all diluted in buffer A. After centrifugation at 38,000 rpm for $16 \mathrm{~h}$ in a SW41 rotor (Beckman Coulter) at $4^{\circ} \mathrm{C}, 1 \mathrm{~mL}$ fractions were harvested from the top. Detection of cholesterol was performed using the Amplex Red Cholesterol assay kit (Invitrogen) according to the instructions of the manufacturer. Protein concentration was determined using by the bicinchoninic acid assay (Pierce- Thermo Fisher Scientific, Brebières, France).

\section{Cholesterol depletion}

Three different methods were used to specifically remove cholesterol. Differentiated HT-29 cells were washed three times in PBS and then incubated in serum-free DMEM containing 4 $\mathrm{mM}$ methyl-beta-cyclodextrin (MCD) for 6 hours at $37^{\circ} \mathrm{C}$ or 2 unit/mL of cholesterase oxidase for $2 \mathrm{~h}$ at $37^{\circ} \mathrm{C}$. Differentiating medium containing Amphotericin B $(25 \mu \mathrm{g} / \mathrm{mL})$ was added every day in HT-29 cells.

\section{Co-immunoprecipitation experiments}

$500 \mu \mathrm{L}$ of gradient fractions (generally fractions $\mathrm{n}^{\circ} 3$ and 11 ) were incubated 2 hours at $4^{\circ} \mathrm{C}$ with $2 \mu \mathrm{g}$ of IgG2a isotype coupled to protein A-Sepharose (GE Healthcare). After a 10 min 
centrifugation at $14000 \mathrm{rpm}$, the supernatants were incubated overnight at $4^{\circ} \mathrm{C}$ with $2 \mu \mathrm{g}$ of antibodies raised against p120ctn or E-cadherin and immobilized on protein A-Sepharose. Beads were washed four times in PBS, and bound proteins were eluted from the beads by boiling in $20 \mu \mathrm{L}$ of Laemmli's sample buffer. The samples were analyzed by western blot.

\section{Western-blot Analysis}

Cells were lysed and extracts processed as previously described [29]. Antibodies dilutions were 1:1000 for E-cadherin, p120ctn, flotillin-1, Rac1; 1:5000 for villin, and 1:250 for actin and p27kip1. In each experiment, actin expression was used as a loading control.

\section{Immunofluorescence microscopy}

Cells grown on glass coverslips were treated as previously described [29]. Antibodies dilutions were: anti-p120ctn and anti E-cadherin (1:200), anti-villin (1:500), FITC-CTx $(1 \mu \mathrm{g} / \mathrm{mL})$ and 1:1000 for secondary antibodies. Coverslips were permanently mounted with Mowiol (Calbiochem). Fluorescence photomicrographs were taken using a confocal laser scanning microscope (Zeiss LSM 510).

Rats proximal colons were collected, fixed over night in PFA 4\%/sucrose 3\% and cryoprotected 12 hours in sucrose $30 \%$ until freezing in isopentane. Samples of 3 different rats were embedded in Tissue-Teck OCT compound cryosectioned at $30 \mu \mathrm{m}$ thickness and performed for immunofluorescence on Superfrost plus slides. Confocal Immunofluorescent sections were acquired using a Leica TCS SPE confocal microscope. 


\section{Rac1-GTP pull-down assays}

Levels of active Rac1 were estimated using the Rac-binding domain of p21-activated kinase (PAK, CRIB) as previously described [30] and adapted by [29]). GTP-bound Rac1 was analyzed by western blotting with anti-Rac1 antibody. Whole cell lysates were run in parallel.

\section{Enzymatic activity assays}

Cell lysate procedure was adapted from [31]. Briefly, the cells were resuspended in $5 \mathrm{mM}$ $\mathrm{Na}_{2} \mathrm{SO}_{4}, 1 \mathrm{mM}$ Tris/HCl, $\mathrm{pH} 7.6,40 \mu \mathrm{g} / \mathrm{ml} \mathrm{PMSF}$ and sonicated for $30 \mathrm{sec}$ at $4^{\circ} \mathrm{C}(400$ joules/watt.sec). Then the homogenate was centrifuged for $10 \mathrm{~min}$ at $1060 \mathrm{~g}$. The supernatant was collected for the enzymatic assays. Alkaline phosphatase activity was measured in 50 $\mathrm{mM}$ glycine $\mathrm{pH} 10.5,0.2 \mathrm{mM} \mathrm{MgCl}_{2}, 5 \mathrm{mM} \mathrm{CaCl}_{2}$ and $2 \mathrm{mM} \mathrm{ZnCl}_{2}$ with $10 \mathrm{mM}$ nitrophenylphosphate disodium salt (Sigma-Aldrich) as substrate during 2 hours at $37^{\circ} \mathrm{C}$ and stopped by the addition of $1 \mathrm{~mole} / \mathrm{L} \mathrm{NaOH}$. The production of $p$-nitrophenol was estimated by measuring the optical density at $420 \mathrm{~nm}$. Dipeptidyl dipeptidase activity was determined by the digestion of $3 \mathrm{mM}$ GlyPro-p-nitroanilide (Sigma-Aldrich) by cell lysates for 30 minutes at $37^{\circ} \mathrm{C}$. The reaction was stopped with $1 \mathrm{M}$ acetate and reaction products were measured at 420 $\mathrm{nm}$. Results are expressed as enzyme activity in international units per milligram of protein. All experiments were performed in triplicates.

\section{Statistical analysis}

All the experiments were performed at least three times. Values are expressed as mean \pm standard error of the mean. 


\section{Results}

\section{E-cadherin and p120ctn translocate into LR during HT-29 cell differentiation}

In epithelial cells, LR are essentially organized at the apical plasma membrane of differentiated cells where they serve as platforms for cell signaling and membrane trafficking. We previously showed that HT-29 cell differentiation results in morphological changes associated with modifications of intercellular junctions [11]. To test whether LR organization and intercellular adhesion are associated during epithelial differentiation, we performed a time-course analysis of LR distribution during the first ten days of HT-29 cell differentiation. Binding of FITC- cholera toxin (FITC-CTx), which presents a high affinity for LR-associated ganglioside GM1 [32], was used as a marker. Fluorescence microscopy analysis showed that the FITC-CTx staining evolves from diffuse at the cell cortex (day 0) to condensed membranous patches (day 4) which accumulate until day 10 (Figure 1A). Furthermore, expression levels of flotillin-1, a component of LR in intestinal cells, gradually increased during the first ten days of HT-29 cell differentiation (Figure 1B). FITC-CTx and flotillin-1 labeling of rat colon cryosections, confirmed that similar LR organization occurs in vivo during intestinal differentiation. Indeed, the two signals were colocalized and more intense at the top of the crypts (upper crypt with differentiated cells) than in the bottom (lower crypt with undifferentiated cells) (Figure 1C). Taken together, these results indicate that LR emergence correlates to enterocytic differentiation.

HT-29 cell differentiation is characterized by a transition from immature to mature Ecadherin-dependent cell-cell contacts, a process linked to the recruitment of p120ctn [11, 29]. To determine whether LR are involved in this process, these microdomains were isolated by centrifugation on a sucrose gradient. Each fraction was subjected to SDS-PAGE followed by immunoblotting with flotillin-1 and actin antibodies (Figure 2A). Flotillin-1 and cholesterol 
were enriched in fractions 3-5, corresponding to LR. Analysis of the gradient protein profile shows that only few proteins were retained in LR fractions, while overall proteins were localized in the high-density bottom fractions (fractions 9-12) corresponding to plasma and vesicular membranes (Figure 2A, grey dashed line). LR and membrane fractions were prepared from HT-29 cells undergoing differentiation and the expression level of E-cadherin and p120ctn in each fraction was analyzed by immunoblotting (Figure 2B). The quality of purification was assessed by the detection of flotillin-1 only in the LR fractions whatever the stage of cell differentiation. In undifferentiated HT-29 cells (day 0 to 4), p120ctn and Ecadherin were found in membrane fractions, with only traces amounts in the LR fractions. However, as the differentiation takes place (day 6 to 10), E-cadherin and p120ctn translocate from membrane to LR fractions. Importance of LR in this process has been studied after their disruption, achieved by endocytosis, cholesterol depletion or oxidation, through the addition of amphoterin B, cholesterol oxidase or methyl- $\beta$-cyclodextrin, respectively [33]. Disruption of LR leads to a decrease in the recruitment of E-cadherin and p120ctn in these structures, and conversely, to their accumulation in membrane-enriched fractions (Figure 2C). This effect was more pronounced for p120ctn, which is a cytoplasmic protein, than for E-cadherin, a transmembrane protein. Surprisingly, we noticed an enhance levels of flotillin-1 in the LR of differentiated cells treated with LR destabilizing drugs, in particular, with amphoterin B and methyl- $\beta$-cyclodextrin. While these treatments change the organization of LR (data not shown), these structures still contain flotillin-1. Indeed, amphotericin B treatment produces bigger patches compared to controls which might be enriched in flotillin-1. In contrast, methyl- $\beta$-cyclodextrin treatment modifies the plasma membrane fluidity (and cell morphology) and LR are more scattered within the plasma membrane. Thus, LR domains still contain flotillin-1 even if their organization is affected by either intra-cytoplasmic clustering or diffusion in the plasma membrane. 
The subcellular distribution of these proteins was further characterized by confocal microscopy analysis (Figure 2D). Both E-cadherin and p120ctn were expressed and localized at the cortex of undifferentiated cells (day 0) but they become concentrated in FITC-CTx stained LR in differentiated HT-29 cells (day 10). Z axis reconstructions showed that Ecadherin and p120ctn association with LR preferentially occurs at the apico-basolateral cell junctions. Interestingly, the same colocalization was observed in the upper crypt of rat colon corresponding to epithelial differentiated cells (Figure 2E).

Overall these data indicate that E-cadherin and p120ctn associate with LR during intestinal differentiation in vitro and in vivo, mainly at the apico-basolateral membranes where intercellular contacts are engaged.

\section{p120ctn binding to E-cadherin preferentially occurs in LR}

To further address the impact of AJ components recruitment in LR on intercellular junction assembly during HT-29 cell differentiation, we tested by co-immunoprecipitation the ability of p120ctn to bind E-cadherin according to its subcellular localization (Figure 3). In differentiated HT-29 cells, the amount of E-cadherin/p120ctn complexes increases in both LR and membrane $(\mathrm{Mb})$ fractions (lanes IP). However, densitometric analysis of Ecadherin/p120ctn complexes indicated that the amount of these complexes is higher in LR.

Our results show that the maturation of AJ which occurs during HT-29 cell differentiation correlates with a recruitment of E-cadherin and p120ctn into LR where they form a complex.

The recruitment of p120ctn and E-cadherin into LR are necessary for HT-29 cell differentiation 
We next investigated the individual contribution of p120ctn and LR in the differentiation program of HT-29 cells, by silencing the expression of p120ctn and flotillin-1. Cells treated with p120ctn-specific shRNA (HT-29 $9^{\text {sh } \mathbf{p 1 2 0}}$ cells) displayed a $50 \%$ reduction in the level of p120ctn, associated with a 30\% decrease in E-cadherin expression (Figure 4A). This effect of p120ctn depletion on E-cadherin was already observed [34] and is specific since the levels of flotillin-1 and actin remained unaffected. A shRNA directed against flotillin-1 (HT-29 $9^{\text {sh flot }}$ cells) reduced the expression of flotillin-1 by $70 \%$ with no change in p120ctn and E-cadherin expression. The impact of p120ctn and flotillin-1 reduction on HT-29 cells differentiation was then assessed by following the kinetic of intestinal differentiation marker during 10 days. The enzymatic activities of ALP and DPPIV are known to increase during intestinal cell differentiation [35]. While increasing with time of HT-29 cell differentiation, the activities of these two enzymes were significantly reduced in p120ctn and flotillin-1 shRNA expressing cells when compared to controls (Figure 4B). The silencing of p120ctn and flotillin-1 is not total and leads to a delay in cell differentiation which was confirmed by immunoblotting of p27kip and villin expression (Figure 4C). As for enzymatic activities, the increase in p27kip and villin expression was delayed and lower in both p120ctn and flotillin-1 depleted HT-29 cells. Flotillin-1, p120ctn and E-cadherin expression levels were used as control. These experiments indicate that both p120ctn and flotillin-1 are needed for HT-29 cell differentiation program. However, we have to determine if LR act upstream of AJ proteins, promoting their maturation as complexes allowing differentiation signals.

The colocalization of E-cadherin and p120ctn with LR was analyzed in differentiated HT-29 cells (day 10) silenced by RNAi. p120ctn and E-cadherin were recruited into LR in control shRNA cells (Figure 5A). Silencing of p120ctn had no effect on the formation of LR, still present as patches at the cell cortex. Impaired expression of p120ctn leads to a reduction of p120ctn as well as E-cadherin recruitment into LR (Figures 5A and 5B). On the opposite, 
the silencing of flotillin-1 impaired the formation of LR in HT-29 cells and lead to a diffuse localization of E-cadherin and p120ctn. This result was confirmed by biochemical analysis of the distribution of p120ctn and E-cadherin in the remaining LR fractions of HT-29 ${ }^{\text {shflot }}$ cells (Figure 5B). Densitometric analyses indicate that the recruitment of E-cadherin and p120ctn in LR is inhibited by $50 \%$ in HT-29 $9^{\text {shp120ctn }}$ cells and by $60 \%$ and $80 \%$ respectively in HT$29^{\text {shflot }}$ cells (Figure 5C).

Therefore, during HT-29 cell differentiation, flotillin-1 is required for LR emergence which thus acts upstream of $\mathrm{AJ}$ protein recruitment and signalling.

\section{Rac1 activation is required for E-cadherin and p120ctn recruitment into $L R$ and}

\section{induction of HT-29 cell differentiation}

The small GTPase Rac1 has been described to regulate AJ assembly in several systems [36]. We thus investigated the relationship between Rac1, LR emergence and AJ maturation in intestinal cell differentiation. For this purpose, we established an HT-29 cell line expressing a dominant negative form of Rac1 (HT-29 Rac1N17). In these cells, the Rac1 activity is inhibited by approximately $60 \%$ and did not vary during the differentiation process compared to control cells (expressing pBabe vector alone) (Figure 6A).

The kinetic of intestinal differentiation markers were compared in these two cell lines: ALP and DPPIV enzymatic activities were respectively delayed and diminished by $50 \%$ and $70 \%$ in HT-29 Rac1N17 at 10 days of differentiation (Figure 6B). In this cell line, the increase of villin expression was also impaired and the protein was not enriched at the apical surface compared to control cells (Figure 6C). The presence of FITC-CTx aggregates at the cortex of HT-29 Rac1N17 cells suggests that LR emergence may occurs in the presence of reduced Rac1 activity. However, levels of flotillin-1 recruited in these LR were slightly reduced in HT-29 Rac1N17 cells compared to control cells (Figure 7). This observation 
indicates that Rac1 activity is required for LR emergence. To test whether Rac1 activity has a role in the recruitment of $\mathrm{AJ}$ components in the LR, we performed p120ctn and E-cadherin immunostainings in differentiated HT-29 pBabe or HT-29 Rac1N17 cells. While these two cell lines expressed similar level of E-cadherin and p120ctn (Figure 7A), we observed that p120ctn and E-cadherin do not colocalize with FITC-CTx labeling in HT-29 Rac1N17 whereas they do in HT-29 cells (Figure 7B). Analysis of the protein profile along the sucrose gradient performed on HT-29 pBabe and HT-29 Rac1N17 cells differentiated for 10 days, showed that p120ctn and E-cadherin were present in LR (fractions 3 to 5) only in control HT29 cells (Figure 7C, left panel). Interestingly, the p190RhoGAP, known to interact and regulate AJ stability downstream of Rac1 [37], was also enriched in HT-29 cells LR fractions but not in HT-29 Rac1N17 cells. As down-regulation of Rac1 activity reduced flotillin-1 expression, a process associated to p120ctn and E-cadherin recruitment in LR, we compared the p120ctn and E-cadherin ratios relative to flotillin-1 (Figure 7C, right panel). Histograms confirmed that p120ctn and E-cadherin recruitment into LR is quantitatively reduced in Rac1N17 by a factor 3.7 and 2.8 respectively.

Collectively, our data demonstrate that Rac1-mediated recruitment of p120ctn and Ecadherin in LR is involved in HT-29 cell intestinal differentiation. To further characterize the sequence of events that occurs during enterocytic differentiation of HT-29 cells, we compared the kinetic of Rac1 activity during the first 10 days of differentiation of the different sh HT-29 cell lines by GST-pulldown assays (Figure 8). In control cells, two peaks of Rac1-GTP were observed at day 0 and days 4 which corresponds to the onset of differentiation marker expression (Figures 6B). Similar Rac1 activation was obtained with shControl cells (Figure 8, upper panel). As expected, a shRNA directed towards flotillin-1 reduces the activation of Rac1 but only during the early steps of differentiation (from 0 to 4 days of differentiation), Rac1 activation being stabilized to a wild-type level at 10 days of differentiation. This result 
indicates that flotillin-1 is earlier required to activate Rac1. Surprisingly, a shRNA targeting p120ctn leads to an increase in Rac-1 activity, although p120ctn have been documented as a Rac and Cdc-42 activator [12,37] (Figure 8, lower panel). This discrepancy may be explained by the different isoforms of Rac1 (Rac1 and Rac1b) expressed in HT-29 cells [29]. At the beginning of differentiation, we could only observe Rac1b in HT-29 shp120ctn cells indicating that this isoform represent the only activated form and could compensate the lack of Rac1. In these cells, the reduced expression of p120ctn is effectively correlated with Rac1 down-regulation. Interestingly Rac1 expression appears at day 6 according to the expression of differentiation markers. Altogether, these data suggest that Rac1 activity lies downstream of flotillin-1 and LR emergence.

\section{Discussion}

Clustering of specialized proteins into LR has been described to be associated to several differentiation processes [38]. Our results indicate that HT-29 cell differentiation is associated with the emergence and clustering of LR. LR are known to organize trafficking at the apical brush border of enterocytes [39] and play a role in the organization of cell adhesion complexes at the basolateral side [40]. This work provides evidences that LR also participate in AJ maturation. We demonstrate that E-cadherin and p120ctn are recruited into LR, which in turn favours p120ctn-binding to E-cadherin and maturation of AJ. These results are consistent with work on myoblasts showing that $\mathrm{N}$-cadherin associates with p120ctn specifically in LR at the cell contacts [23]. The recruitment of cadherins in LR may account for their stabilization, but also allows the scaffolding of signalling molecules involved in the dynamic and the function of AJ. The mechanism of cadherin recruitment in LR is still unclear and one can wonder whether immature AJ proteins freely diffuse in the plasma membrane and are stopped in their diffusion in the LR, thereby resulting in local enrichment; or whether 
these immature AJ are already present in small raft domains that cluster to give rise to larger domains. The gradual patching of GM1 observed at the plasma membrane during HT-29 cell differentiation, argues for the later mechanism. Concomitantly, E-cadherin and p120ctn which are distributed all-around the cell membrane before differentiation become more colocalized with LR, suggesting that these proteins are progressively recruited in growing rafts. The presence of potential Cholesterol recognition/interaction Amino Acid Consensus in the Cterminal region of p120ctn might be involved in the localization of this protein in LR [41]. The recruitment of adhesion molecules into LR could depend on flotillin-1. Indeed, we noticed an up-regulation of flotillin-1 expression during HT-29 cell differentiation which is probably associated with increasing confluence and to the presence of motifs for binding transcription factors involved in cell differentiation in the promoter region of flotillin-1 [42]. Our results show that silencing of flotillin-1 strongly reduces the recruitment of p120ctn and E-cadherin in LR and delays HT-29 cell differentiation, suggesting that blocking the translocation of these molecules in LR alters adhesive complex functionality. The available data on interference with flotillin function during development of zebrafish and imaginal discs in Drosophilia points to an important role for flotillin in regulating formation of cell-cell contacts during morphogenesis [43]. Emerging evidence suggests that flotillin plays a role in the regulation of actin cytoskeleton organization and enhances the spreading of cells on extracellular matrix-coated surface in a phosphorylation dependent manner [44]. Similarly, a src family kinase dependent phosphorylation of flotillin [45, 46] may also regulate the maturation of cell adhesion complexes and their association with the actin cytoskeleton.

Our work also pointed at a major role for Rac1 in LR-mediated intestinal differentiation. Consistent with previous studies demonstrating roles for Rac and Rho in regulating AJ assembly [47, 48], we found that an antagonism between the activities of these 
two GTPases is necessary for E-cadherin dependent cell-cell contacts during HT-29 cell differentiation (supplementary data). RhoA activity is necessary for cell proliferation as it was observed in the intestinal crypt, while inhibition of RhoA activity occurs into differentiating intestinal epithelium $[49,50]$. The Rho-Rac antagonism observed during AJ assembly could be mediated by the activation of the p190RhoGAP. Rac1 activity causes translocation of p190RhoGAP to AJ, where it couples to cadherin complex via p120ctn and induces a local inhibition of Rho [37]. In intestinal cells this interaction occurs in LR since we found that p190RhoGAP is recruited together with E-cadherin and p120ctn and that Rac1 is necessary for this step. The Rho/Rac antagonism could also be associated to flotillin-1 recruitment in LR: indeed, in neurons the flotillin-mediated recruitment of CAP/ponsin to focal contacts is crucial for the balanced activation of the Rho-GTPases [28]. During HT-29 cell differentiation, early Rac1 activity could favour plasma membrane protrusions and contacts $[51,52]$ and then RhoA activation could increase the actomyosin contractility locally and thereby concentrate cadherin dimmers [53]. Silencing of flotillin-1 altered this initial activation of Rac1, indicating that Rac1 activity lies downstream of flotillin-1 and LR emergence. The second peak of Rac1 activity correlates with E-cadherin and p120ctn recruitment into LR, suggesting that Rac1 activation could favour this process. This hypothesis was confirmed using HT-29 Rac1N17 cells, in which E-cadherin and p120ctn were no longer recruited in LR and failed to colocalize. At this stage, shflotillin-1 didn't affect Rac1 activation probably by a compensatory mechanism between the different member of flotillin 's family. The fact that Rac1 activation correlates with LR accumulation at the site of AJ suggests a specific signalling of Rac1 at this stage, probably to build mature AJ and to fully differentiate epithelial cells. This is confirmed by the fact that HT-29 Rac1N17 cells show a delay in the emergence of differentiation markers. A similar mechanism has been proposed for cell- matrix adhesion, and is regulated by integrins [54]. 
Recent report indicates that p120ctn is essential for barrier function and intestinal epithelial homeostasis. P120 conditional $\mathrm{KO}$ in mice small intestine and colon is characterized by barrier defects resulting from a selective loss of adherens junctions [55]. Using HT-29 cells silenced for p120ctn we show that p120ctn is required for AJ-associated cell differentiation. In this process, p120ctn may act at different steps: 1) by stabilizing Ecadherin at the plasma membrane and thus contributing to mature AJ able to activate specific intestinal transcription factors $[5,6]$; 2) by coordinating Rho-GTPases activities. Our results indicate that Rac1 regulates p120ctn recruitment in LR where it could participate in the amplification of Rac1 signalisation. Indeed the delayed differentiation observed in shp120ctn cells is similar to the one observed in Rac1N17 cells. The residual differentiation observed in these two models can be attributed to the partial down-regulation of p120ctn /or Rac1 expression and the maintenance of some Rac1 activity.

In conclusion, the LR-dependent association of p120ctn with E-cadherin, provides new insight into the crucial role of p120ctn as a "positive regulator" of E-cadherin function in intestinal cell differentiation. Interestingly, E-cadherin and p120ctn expression has been shown to be down-regulated in inflammatory bowel disease [56] . Furthermore alteration of flotillin-1 expression is observed in TNBS-induced colitis in mice [57]. Thus, modification of LR structure and adherens junctions function would be associate to barrier alteration and inflammation.

\section{Acknowledgments}

We thank Alexandre Chatelain, Alexei Grichine and Brigitte Peyrusse for their expert technical assistance in confocal microscopy and the reprography artwork. Grant support: Association pour la Recherche sur le Cancer, Ligue Nationale contre le Cancer (Comité de Savoie), Groupement des Entreprises Françaises dans la lutte contre le Cancer and Espoir. N. 
Chartier and B. Ducarouge were the recipient of a fellowship from the Ministère de la Recherche et de l'Enseignement Supérieur.

References

[1] D. Clayburgh, L. Shen, J. Turner, A porous defense: the leaky epithelial barrier in intestinal disease., Lab Invest 84 (2004) 282-291.

[2] B.M. Gumbiner, Regulation of cadherin adhesive activity, J Cell Biol 148 (2000) 399-404.

[3] M. Perez-Moreno, E. Fuchs, Catenins: keeping cells from getting their signals crossed., Dev Cell 11 (2006) 601-612.

[4] B.M. Gumbiner, Regulation of cadherin-mediated adhesion in morphogenesis, Nat Rev Mol Cell Biol 6 (2005) 622-634.

[5] P. Laprise, P. Chailler, M. Houde, J.F. Beaulieu, M.J. Boucher, N. Rivard, Phosphatidylinositol 3-kinase controls human intestinal epithelial cell differentiation by promoting adherens junction assembly and p38 MAPK activation, J Biol Chem 277 (2002) 8226-8234.

[6] G. Peignon, S. Thenet, C. Schreider, S. Fouquet, A. Ribeiro, E. Dussaulx, J. Chambaz, P. Cardot, M. Pincon-Raymond, J. Le Beyec, E-cadherin-dependent transcriptional control of apolipoprotein A-IV gene expression in intestinal epithelial cells: a role for the hepatic nuclear factor 4, J Biol Chem 281 (2006) 3560-3568.

[7] J.M. Mariadason, M. Bordonaro, F. Aslam, L. Shi, M. Kuraguchi, A. Velcich, L.H. Augenlicht, Down-regulation of beta-catenin TCF signaling is linked to colonic epithelial cell differentiation, Cancer Res 61 (2001) 3465-3471.

[8] A.B. Reynolds, R.H. Carnahan, Regulation of cadherin stability and turnover by p120ctn: implications in disease and cancer, Semin Cell Dev Biol 15 (2004) 657663.

[9] M.A. Davis, R.C. Ireton, A.B. Reynolds, A core function for p120-catenin in cadherin turnover, J Cell Biol 163 (2003) 525-534.

[10] R.C. Ireton, M.A. Davis, J. van Hengel, D.J. Mariner, K. Barnes, M.A. Thoreson, P.Z. Anastasiadis, L. Matrisian, L.M. Bundy, L. Sealy, B. Gilbert, F. van Roy, A.B. Reynolds, A novel role for p120 catenin in E-cadherin function, J Cell Biol 159 (2002) 465-476.

[11] S. Gout, C. Marie, M. Laine, G. Tavernier, M.R. Block, M. Jacquier-Sarlin, Early enterocytic differentiation of HT-29 cells: biochemical changes and strength increases of adherens junctions, Exp Cell Res 299 (2004) 498-510.

[12] P.Z. Anastasiadis, p120-ctn: A nexus for contextual signaling via Rho GTPases, Biochim Biophys Acta 1773 (2007) 34-46.

[13] jaffe, in: Hall (Ed.), 2005.

[14] M. Fukata, K. Kaibuchi, Rho-family GTPases in cadherin-mediated cell-cell adhesion, Nat Rev Mol Cell Biol 2 (2001) 887-897. 
[15] S. Samarin, A. Nusrat, Regulation of epithelial apical junctional complex by Rho family GTPases, Front Biosci 14 (2009) 1129-1142.

[16] V.M. Braga, A. Del Maschio, L. Machesky, E. Dejana, Regulation of cadherin function by Rho and Rac: modulation by junction maturation and cellular context, Mol Biol Cell 10 (1999) 9-22.

[17] A.S. Yap, E.M. Kovacs, Direct cadherin-activated cell signaling: a view from the plasma membrane, J Cell Biol 160 (2003) 11-16.

[18] K. Takaishi, T. Sasaki, H. Kotani, H. Nishioka, Y. Takai, Regulation of cell-cell adhesion by rac and rho small G proteins in MDCK cells, J Cell Biol 139 (1997) 1047-1059.

[19] S. Schuck, K. Simons, Polarized sorting in epithelial cells: raft clustering and the biogenesis of the apical membrane, J Cell Sci 117 (2004) 5955-5964.

[20] P. Niethammer, M. Delling, V. Sytnyk, A. Dityatev, K. Fukami, M. Schachner, Cosignaling of NCAM via lipid rafts and the FGF receptor is required for neuritogenesis, J Cell Biol 157 (2002) 521-532.

[21] B. van Deurs, K. Roepstorff, A.M. Hommelgaard, K. Sandvig, Caveolae: anchored, multifunctional platforms in the lipid ocean, Trends Cell Biol 13 (2003) 92-100.

[22] A. Nusrat, C.A. Parkos, P. Verkade, C.S. Foley, T.W. Liang, W. InnisWhitehouse, K.K. Eastburn, J.L. Madara, Tight junctions are membrane microdomains, J Cell Sci 113 ( Pt 10) (2000) 1771-1781.

[23] N. Taulet, F. Comunale, C. Favard, S. Charrasse, S. Bodin, C. GauthierRouviere, N-cadherin/P120 catenin association at cell-cell contacts occurs in cholesterol-rich membrane domains and is required for rhoa activation and myogenesis, J Biol Chem (2009).

[24] M.F. Langhorst, A. Reuter, C.A. Stuermer, Scaffolding microdomains and beyond: the function of reggie/flotillin proteins, Cell Mol Life Sci 62 (2005) 22282240 .

[25] E.V. Vassilieva, A.I. Ivanov, A. Nusrat, Flotillin-1 stabilizes caveolin-1 in intestinal epithelial cells, Biochem Biophys Res Commun 379 (2009) 460-465.

[26] T. Babuke, R. Tikkanen, Dissecting the molecular function of reggie/flotillin proteins, Eur J Cell Biol 86 (2007) 525-532.

[27] J. Liu, S.M. Deyoung, M. Zhang, L.H. Dold, A.R. Saltiel, The stomatin/prohibitin/flotillin/HflK/C domain of flotillin-1 contains distinct sequences that direct plasma membrane localization and protein interactions in 3T3-L1 adipocytes, J Biol Chem 280 (2005) 16125-16134.

[28] M.F. Langhorst, F.A. Jaeger, S. Mueller, L. Sven Hartmann, G. Luxenhofer, C.A. Stuermer, Reggies/flotillins regulate cytoskeletal remodeling during neuronal differentiation via CAP/ponsin and Rho GTPases, Eur J Cell Biol 87 (2008) 921-931.

[29] N.T. Chartier, M. Laine, S. Gout, G. Pawlak, C.A. Marie, P. Matos, M.R. Block, M.R. Jacquier-Sarlin, Laminin-5-integrin interaction signals through PI 3-kinase and Rac1b to promote assembly of adherens junctions in HT-29 cells, J Cell Sci 119 (2006) 31-46.

[30] E.E. Sander, S. van Delft, J.P. ten Klooster, T. Reid, R.A. van der Kammen, F. Michiels, J.G. Collard, Matrix-dependent Tiam1/Rac signaling in epithelial cells promotes either cell-cell adhesion or cell migration and is regulated by phosphatidylinositol 3-kinase, J Cell Biol 143 (1998) 1385-1398. 
[31] B. Stieger, A. Marxer, H.P. Hauri, Isolation of brush-border membranes from rat and rabbit colonocytes: is alkaline phosphatase a marker enzyme?, J Membr Biol 91 (1986) 19-31.

[32] E.A. Merritt, S. Sarfaty, F. van den Akker, C. L'Hoir, J.A. Martial, W.G. Hol, Crystal structure of cholera toxin B-pentamer bound to receptor GM1 pentasaccharide, Protein Sci 3 (1994) 166-175.

[33] E.J. Smart, R.G. Anderson, Alterations in membrane cholesterol that affect structure and function of caveolae, Methods Enzymol 353 (2002) 131-139.

[34] A.P. Kowalczyk, A.B. Reynolds, Protecting your tail: regulation of cadherin degradation by p120-catenin, Curr Opin Cell Biol 16 (2004) 522-527.

[35] A. Quaroni, J.Q. Tian, P. Seth, C. Ap Rhys, p27(Kip1) is an inducer of intestinal epithelial cell differentiation, Am J Physiol Cell Physiol 279 (2000) C1045-1057.

[36] M. Betson, E. Lozano, J. Zhang, V.M. Braga, Rac activation upon cell-cell contact formation is dependent on signaling from the epidermal growth factor receptor, J Biol Chem 277 (2002) 36962-36969.

[37] G.A. Wildenberg, M.R. Dohn, R.H. Carnahan, M.A. Davis, N.A. Lobdell, J. Settleman, A.B. Reynolds, p120-Catenin and p190RhoGAP Regulate Cell-Cell Adhesion by Coordinating Antagonism between Rac and Rho, Cell 127 (2006) 1027-1039.

[38] M.M. Moreno-Altamirano, I. Aguilar-Carmona, F.J. Sanchez-Garcia, Expression of GM1, a marker of lipid rafts, defines two subsets of human monocytes with differential endocytic capacity and lipopolysaccharide responsiveness, Immunology 120 (2007) 536-543.

[39] E.M. Danielsen, G.H. Hansen, Lipid rafts in epithelial brush borders: atypical membrane microdomains with specialized functions, Biochim Biophys Acta 1617 (2003) 1-9.

[40] T.J. Harris, C.H. Siu, Reciprocal raft-receptor interactions and the assembly of adhesion complexes, Bioessays 24 (2002) 996-1003.

[41] R.M. Epand, Proteins and cholesterol-rich domains, Biochim Biophys Acta 1778 (2008) 1576-1582.

[42] P.P. Lopez-Casas, J. del Mazo, Regulation of flotillin-1 in the establishment of NIH-3T3 cell-cell interactions, FEBS Lett 555 (2003) 223-228.

[43] M. Hoehne, H.G. de Couet, C.A. Stuermer, K.F. Fischbach, Loss- and gain-offunction analysis of the lipid raft proteins Reggie/Flotillin in Drosophila: they are posttranslationally regulated, and misexpression interferes with wing and eye development, Mol Cell Neurosci 30 (2005) 326-338.

[44] C. Neumann-Giesen, I. Fernow, M. Amaddii, R. Tikkanen, Role of EGF-induced tyrosine phosphorylation of reggie-1/flotillin-2 in cell spreading and signaling to the actin cytoskeleton, J Cell Sci 120 (2007) 395-406.

[45] T. Roitbak, Z. Surviladze, R. Tikkanen, A. Wandinger-Ness, A polycystin multiprotein complex constitutes a cholesterol-containing signalling microdomain in human kidney epithelia, Biochem J 392 (2005) 29-38.

[46] C.A. Stuermer, D.M. Lang, F. Kirsch, M. Wiechers, S.O. Deininger, H. Plattner, Glycosylphosphatidyl inositol-anchored proteins and fyn kinase assemble in noncaveolar plasma membrane microdomains defined by reggie-1 and -2, Mol Biol Cell 12 (2001) 3031-3045.

[47] V.M. Braga, M. Betson, X. Li, N. Lamarche-Vane, Activation of the small GTPase Rac is sufficient to disrupt cadherin-dependent cell-cell adhesion in normal human keratinocytes, Mol Biol Cell 11 (2000) 3703-3721. 
[48] F. Comunale, M. Causeret, C. Favard, J. Cau, N. Taulet, S. Charrasse, C. Gauthier-Rouviere, Rac1 and RhoA GTPases have antagonistic functions during $\mathrm{N}$-cadherin-dependent cell-cell contact formation in $\mathrm{C2C12}$ myoblasts, Biol Cell 99 (2007) 503-517.

[49] Y.D. Benoit, C. Lussier, P.A. Ducharme, S. Sivret, L.M. Schnapp, N. Basora, J.F. Beaulieu, Integrin alpha8beta1 regulates adhesion, migration and proliferation of human intestinal crypt cells via a predominant RhoA/ROCK dependent mechanism, Biol Cell (2009).

[50] L.P. Pageot, N. Perreault, N. Basora, C. Francoeur, P. Magny, J.F. Beaulieu, Human cell models to study small intestinal functions: recapitulation of the crypt-villus axis, Microsc Res Tech 49 (2000) 394-406.

[51] J.S. Ehrlich, M.D. Hansen, W.J. Nelson, Spatio-temporal regulation of Rac1 localization and lamellipodia dynamics during epithelial cell-cell adhesion, Dev Cell 3 (2002) 259-270.

[52] E.M. Kovacs, R.G. Ali, A.J. McCormack, A.S. Yap, E-cadherin homophilic ligation directly signals through $R$ ac and phosphatidylinositol 3-kinase to regulate adhesive contacts, J Biol Chem 277 (2002) 6708-6718.

[53] A.M. Shewan, M. Maddugoda, A. Kraemer, S.J. Stehbens, S. Verma, E.M. Kovacs, A.S. Yap, Myosin 2 is a key Rho kinase target necessary for the local concentration of E-cadherin at cell-cell contacts, Mol Biol Cell 16 (2005) 45314542.

[54] M.A. del Pozo, N.B. Alderson, W.B. Kiosses, H.H. Chiang, R.G. Anderson, M.A. Schwartz, Integrins regulate Rac targeting by internalization of membrane domains, Science 303 (2004) 839-842.

[55] W. Smalley-Freed, A. Efimov, P. Burnett, S. Short, M. Davis, D. Gumucio, M. Washington, R. Coffey, A. Reynolds, p120-catenin is essential for maintenance of barrier function and intestinal homeostasis in mice., J Clin Invest 120 (2010) 1824-1835.

[56] A.J. Karayiannakis, K.N. Syrigos, J. Efstathiou, A. Valizadeh, M. Noda, R.J. Playford, W. Kmiot, M. Pignatelli, Expression of catenins and E-cadherin during epithelial restitution in inflammatory bowel disease, J Pathol 185 (1998) 413-418.

[57] Q. Li, Q. Zhang, M. Zhang, C. Wang, Z. Zhu, N. Li, J. Li, Effect of n-3 polyunsaturated fatty acids on membrane microdomain localization of tight junction proteins in experimental colitis., FEBS J 275 (2008) 411-420.

Figure legends

Figure 1: Early enterocytic differentiation of HT-29 cells is associated with the emergence of flotillin-1 LR.

(A) Middle plane confocal sections of HT-29 cells differentiated for 0, 4 or 10 days in Gal-

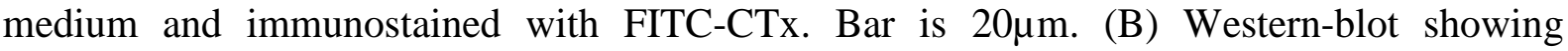


flotillin-1 expression levels in lysate from HT-29 cells differentiated for the indicated times. Histograms represent the densitometric ratio of flotillin-1 to actin levels (mean $+/-$ s.e.m. of three independent experiments). ${ }^{*}, p<0,01$ compared to J0 as determined by Student's $t$-test. (C) Confocal analysis of rat colon cryosections immunostained with FITC-CTx (green) and flotillin-1 (red). Bar $=100 \mu \mathrm{m}$.

Figure 2: AJ proteins are associated with Flotillin-1 enriched LR during HT-29 cells differentiation

(A) Lysates from HT-29 cells differentiated for 10 days was fractionated using a sucrose gradient. The presence of LR was assessed by western-blot against flotillin. Curves indicate the concentration of cholesterol (dark full line) and protein (grey dotted line) for each fraction. (B) Western-blots showing the expression level of p120ctn, E-cadherin and flotillin-1 in LR and in membranes fractions of HT-29 cells differentiated for 10 days. Actin was used as loading control (C) Differentiated HT-29 cells were treated or not with LR destabilizing drugs: amphotericin $\mathrm{B}(\mathrm{AB})$; cholesterol oxidase $(\mathrm{CO})$ and methyl-cyclodextrin (MCD). Then they were fractionated on a sucrose gradient before western-blot analysis. (D) HT-29 cells undifferentiated (day 0) or differentiated (day 10) were immunostained for E-cadherin (left panels) and p120ctn (right panels) together with FITC-CTx. Projection on the Z-axis is presented upon each picture. Bar is $20 \mu \mathrm{m}$. (E) Immunofluorescent labeling of FITC-CTx (green) and E-cadherin (red, upper panel) or p120ctn (red, lower panel) demonstrating colocalization of these proteins (yellow) in the epithelial cells of the rat colon. Bar $=60 \mu \mathrm{m}$.

\section{Figure 3: E-cadherin/p120ctn interaction occurs preferentially in LR.}

P120ctn and E-cadherin were immunoprecipitated from equal volume of LR or membranes fractions of HT-29 cells differentiated for 10 days. The amount of E-cadherin/p120ctn complexes was then assessed by western-blot. Input: $25 \mu \mathrm{L}$ of each fractions; Sup: 
Supernatant of immunoprecipitation; IP: Immunoprecipitate; Control: IgG2a immunoprecipitation. Histograms represent the relative quantity of adherens junctions protein complexes. Quantification of complexes obtained in fractions 3 and 11, was determined as follow: values of densitometry ratio of the co-immunoprecipitated protein bands / immunoprecipitated protein bands.

Figure 4: Flotillin-1 enriched $L R$ and p120ctn are required for intestinal cell differentiation.

(A) Western-blots showing E-cadherin, p120ctn, flotillin-1 and actin expression levels in lysates from HT-29 cells stably expressing the indicated shRNA. Histograms represent the percentage of each protein (average of two different shRNA constructs) compared to control shRNA directed against GFP (mean +/- s.e.m. of three independent experiments). (B) Lysates from shRNA treated cells differentiated from 0 to 10 days were assayed for ALP activity or DPPIV activity. Data represent the mean $+/$ - s.e.m. of three independent experiments. $P$ value (compared to $S h$ control) are determined by Student's $t$-test and correspond to: *, $P$ value $<0,002$ and $*^{*}, P$ value $<0,001$ for ALP activity; and $*, P$ value $<0,05$ and $* *, P$ value $<0,002$ for DPPIV activity. (C) The same lysates were analyzed by western-blot for the expression of the differentiation markers p27kip1, villin and for E-cadherin, p120ctn and flotillin-1.

\section{Figure 5: Flotillin-1 is required for the recruitment of AJ proteins in LR.}

(A) Differentiated HT-29 cells treated with shRNA were immunostained for E-cadherin (or p120ctn together with FITC-CTx. Bar is $10 \mu \mathrm{m}$. (B) Lysates from differentiated HT-29 cells treated with shRNA were fractionated on a sucrose gradient. The levels of E-cadherin, p120ctn and flotillin-1 from LR and membrane fractions were assessed by western-blot. (C) Histograms representing the percentage of each protein into LR compared to control 
conditions in the different $s h$ RNA cell lines (mean +/- s.e.m. of three independent experiments).

Figure 6: Rac1 activity is required for enterocytic differentiation of HT-29 cells.

(A) Rac1 activity was assessed in undifferentiated or differentiated HT-29 cells expressing vector alone (HT-29 pBabe cells) or pBabe Rac1N17 construction (HT-29 Rac1N17 cells). Histograms represent the densitometric ratio of active Rac1-GTP/ Rac1 total (mean +/- s.e.m. of three independent experiments). (B) Lysates from HT-29 pBabe cells and HT-29 Rac1N17 cells differentiated from 0 to 10 days were assayed for ALP activity and DPPIV activity. Data represent the mean +/- s.e.m. of three independent experiments. P value (compared to HT-29 pBabe) are determined by Student's t-test and correspond to: *, P value <0,05 and **, P value $<0,015$ for ALP activity; and *, P value <0,01 for DPPIV activity. (C) Villin expression was analyzed by western-blot in lysates of HT-29 pBabe cells and HT-29 Rac1N17 cells differentiated from 0 to 10 days and by confocal microscopy at 10 days.

\section{Figure 7: Rac1 activity is correlated to E-cadherin/p120ctn complexes recruitment in} lipid rafts.

(A) E-cadherin, p120ctn, flotillin-1 and actin expressions were assessed by western-blot in lysates from HT-29 pBabe and HT-29 Rac1N17 cells differentiated from 0 to 10 days. (B) HT-29 cells expressing the pBabe or the pBabe Rac1N17 constructs were allowed to differentiate for 10 days and immunostained for E-cadherin and p120ctn together with FITCCTx. Bar is $20 \mu \mathrm{m}$. (C) Lysates from differentiated HT-29 pBabe or HT-29 Rac1N17 cells were fractionated on a sucrose gradient. The amount of p120ctn, E-cadherin, flotillin-1 and p190RhoGap in each fraction was assessed by western-blot. Histograms represent the ratio of 
p120ctn or E-cadherin on flotillin-1 in LR fractions (mean +/- s.e.m. of three independent experiments).

\section{Figure 8: Rac1 activity lies downstream of flotillin-1 and LR emergence}

Rac1-GTP was precipitated by GST-PAK pulldown from lysates of control and the different sh HT-29 cells allowed differentiating for 10 days. The levels of active and total Rac1 were analyzed by western-blot. Histograms on upper panel represent the densitometric ratio of active Rac1-GTP/ Rac1 total (mean +/- s.e.m. of two independent experiments) determined in HT-29 cells, and in shControl and shFlotillin HT-29cells. All these lines expressed the both isoforms of Rac1. In contrast, shp120ctn expressed mainly Rac1b isoform, we thus described histogram representing the densitometric ratio of active Rac1-GTP/ total Rac1b (mean +/s.e.m. of two independent experiments) (lower panel). 
A
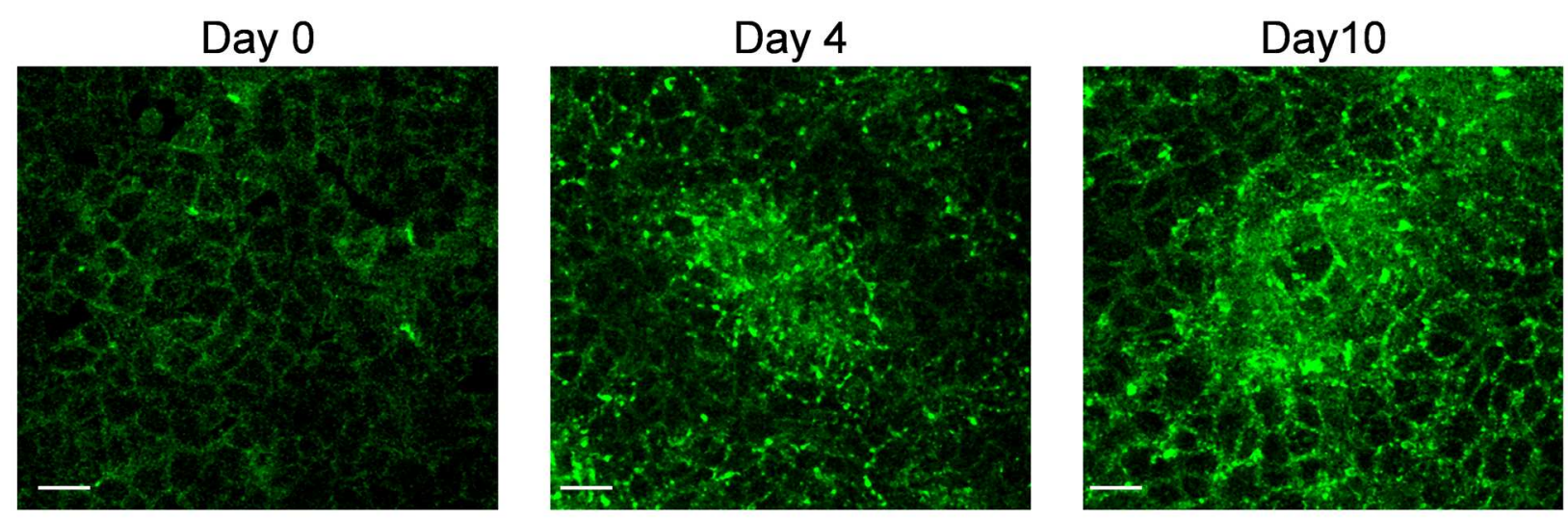

B

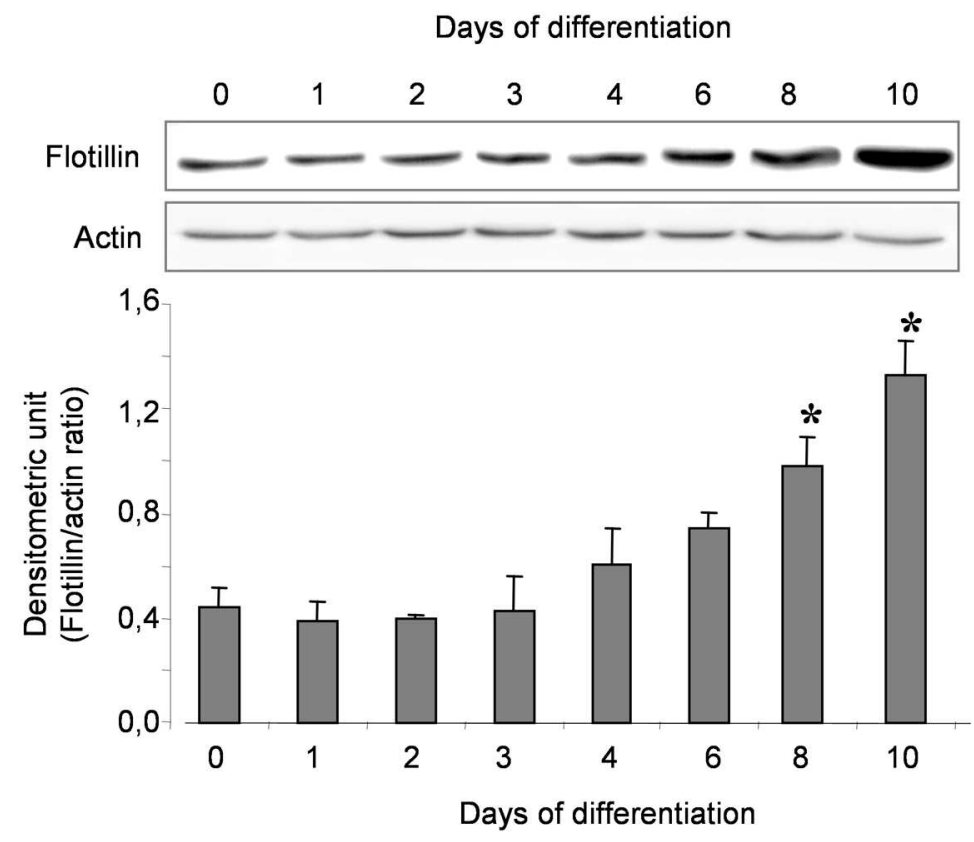

C

\section{Cholera} Toxin (CTx)

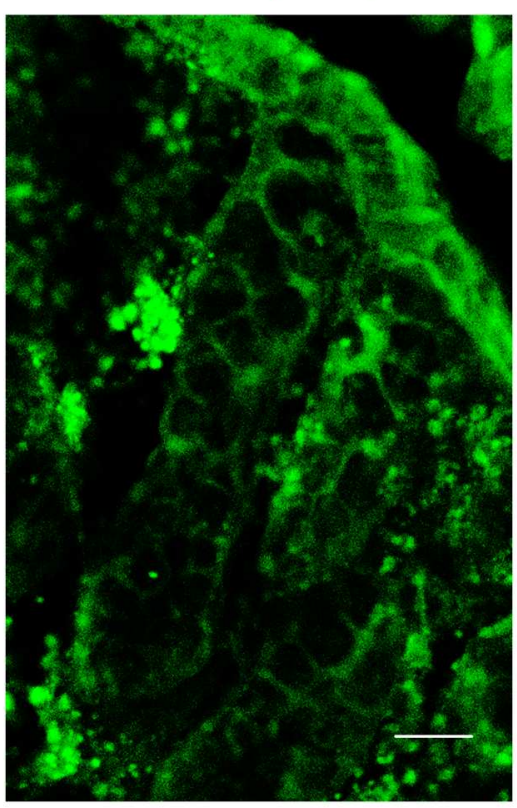

Flotillin

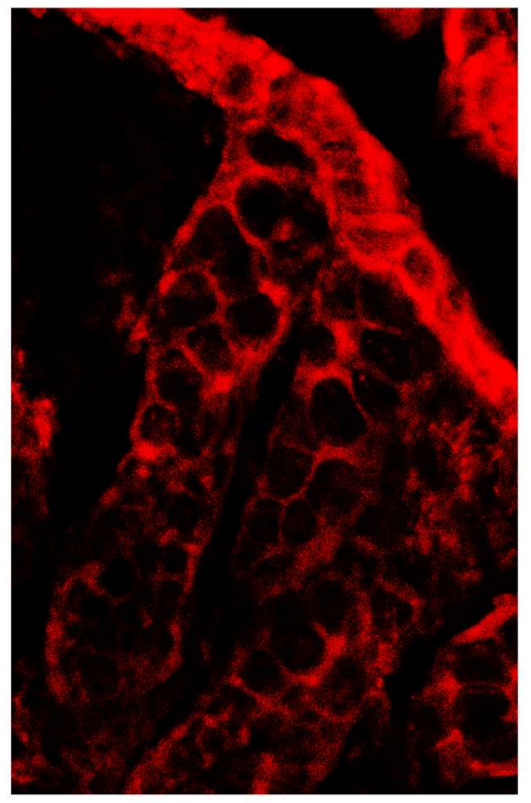

Merge

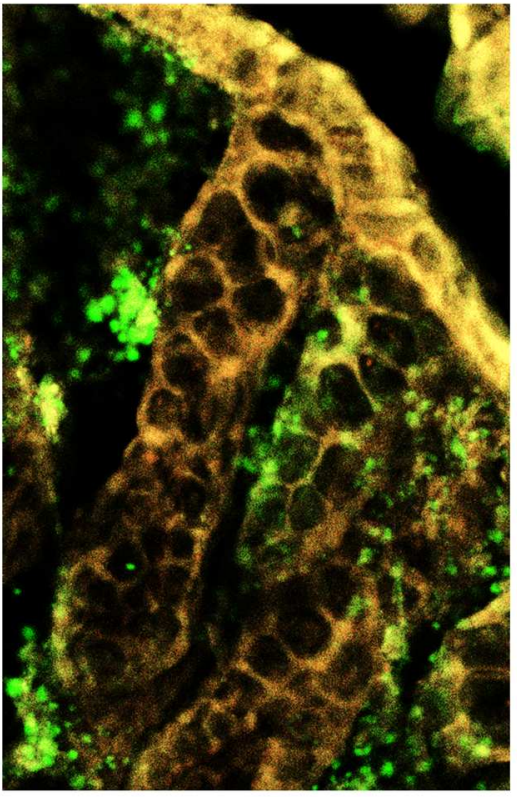

Figure 1 
A Differentiated cells (gradient fraction $\mathrm{N}^{\circ}$ )

B

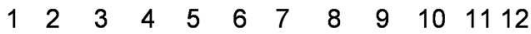

$\begin{array}{ll}+\infty & \text { Flotillin } \\ \longrightarrow \sim & \text { Actin }\end{array}$

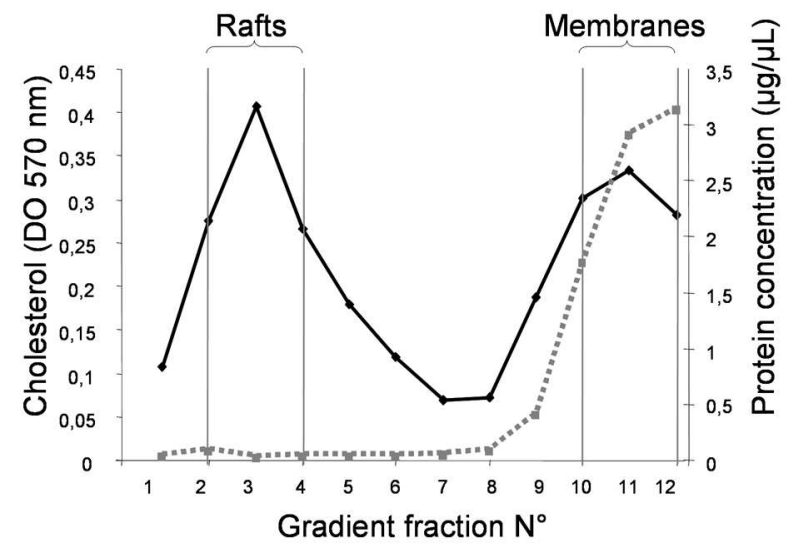

Rafts

Membranes

days of

$\begin{array}{lllllllllllll}\text { differentiation } & 0 & 2 & 4 & 6 & 8 & 10 & 0 & 2 & 4 & 6 & 8 & 10\end{array}$

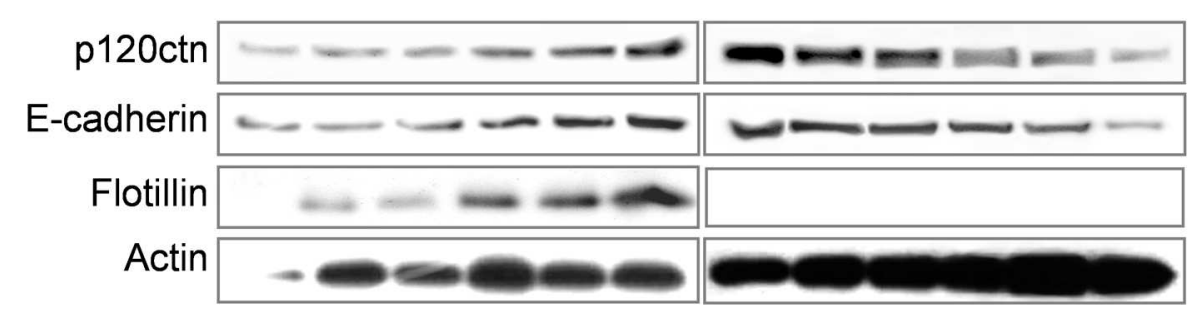

C

Rafts

Membranes

E

Ct AB CO MCD

Ct AB CO MCD
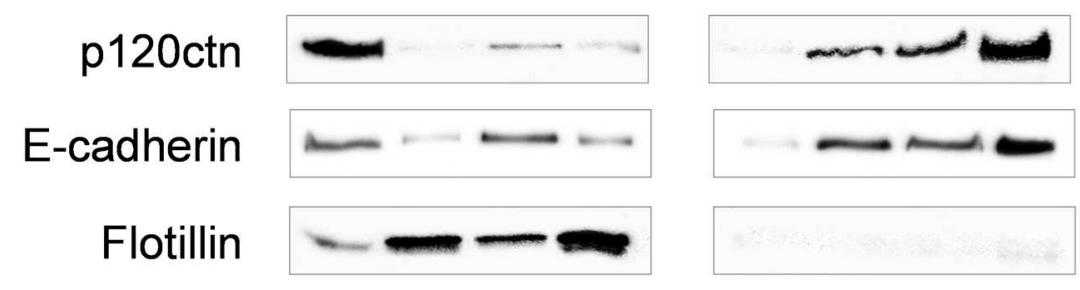

D

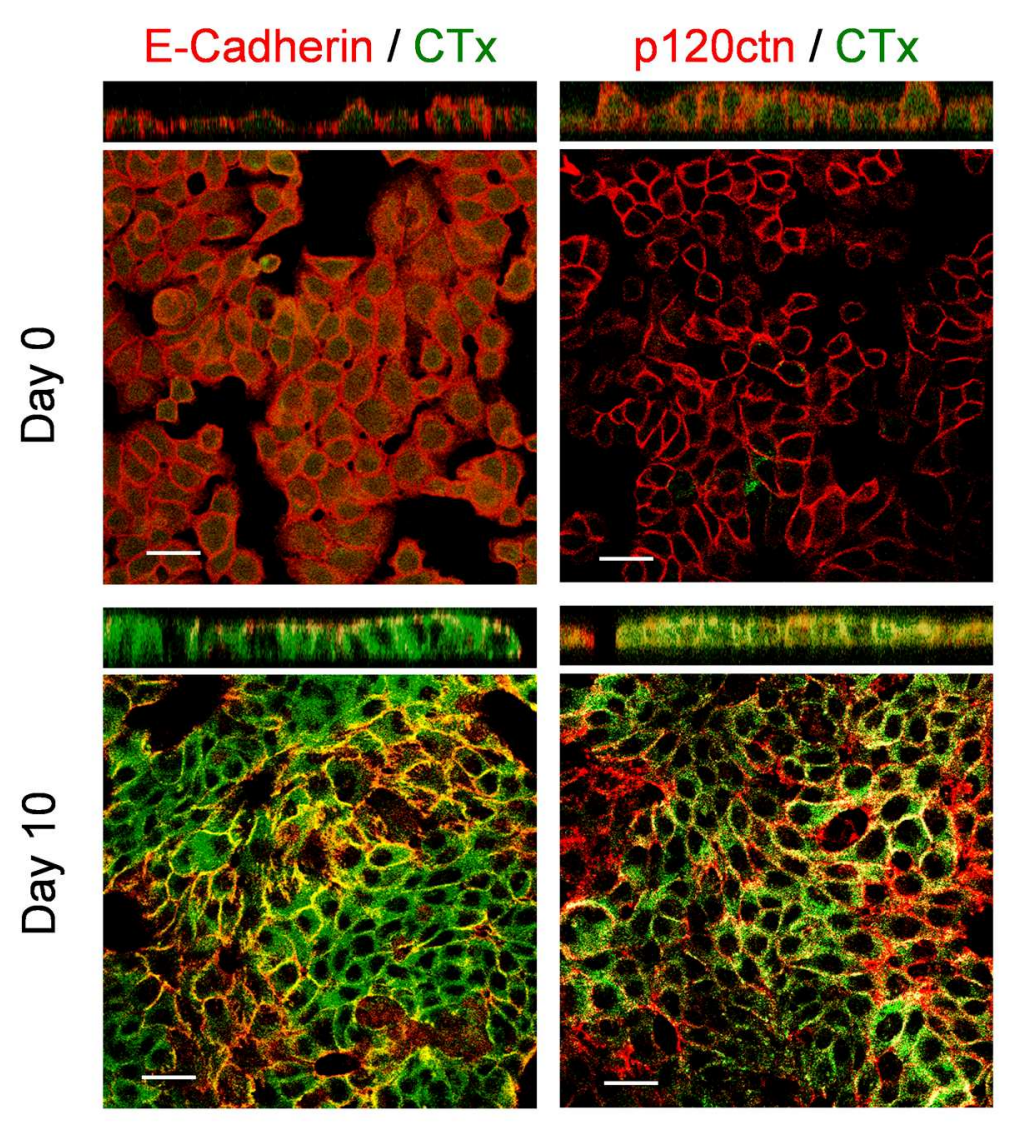

E-Cadherin / CTx

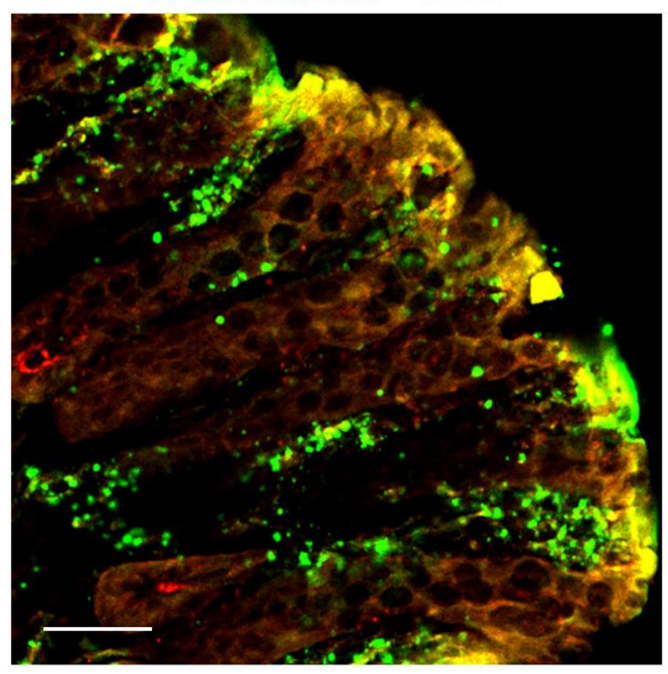

p120ctn / CTx

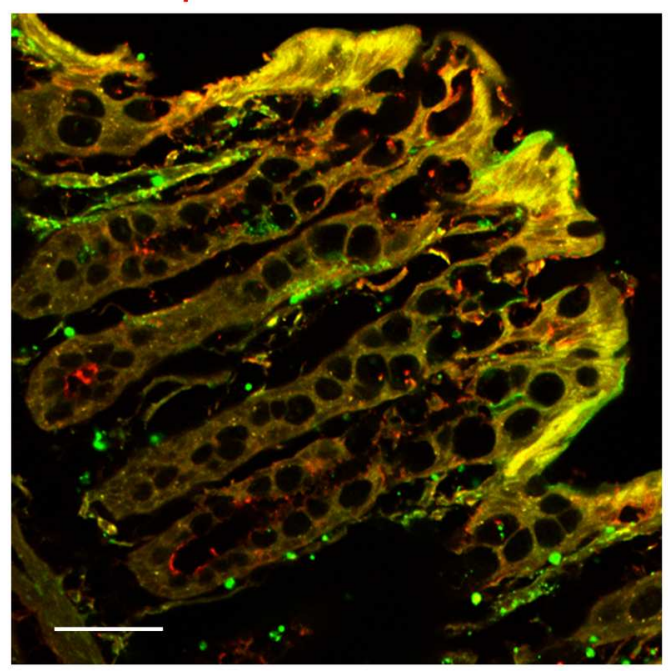



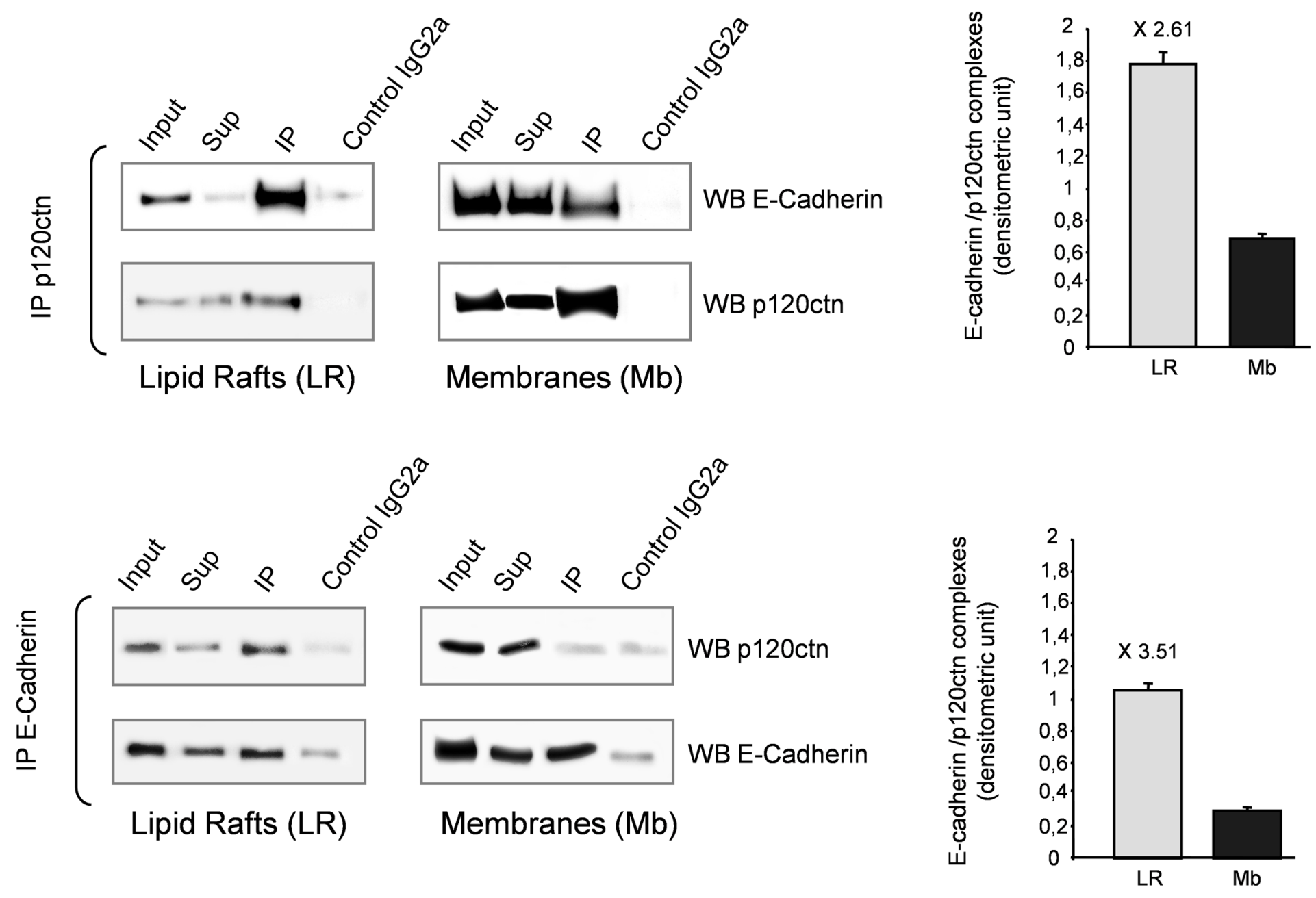

Figure 3 


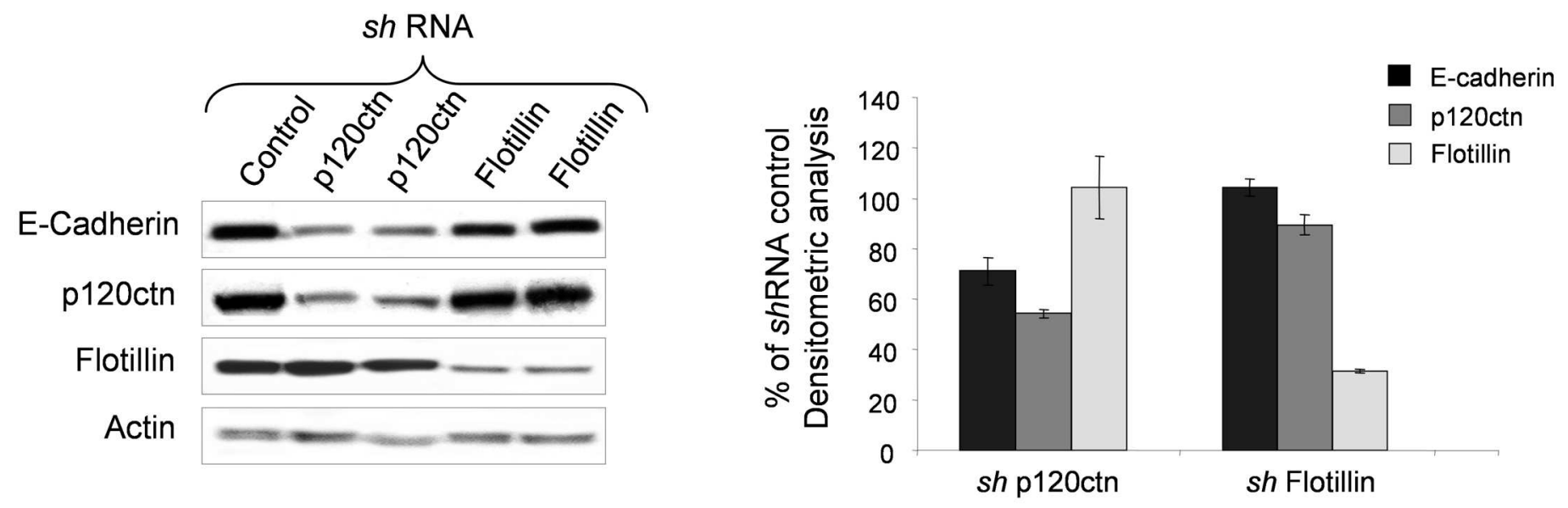

B
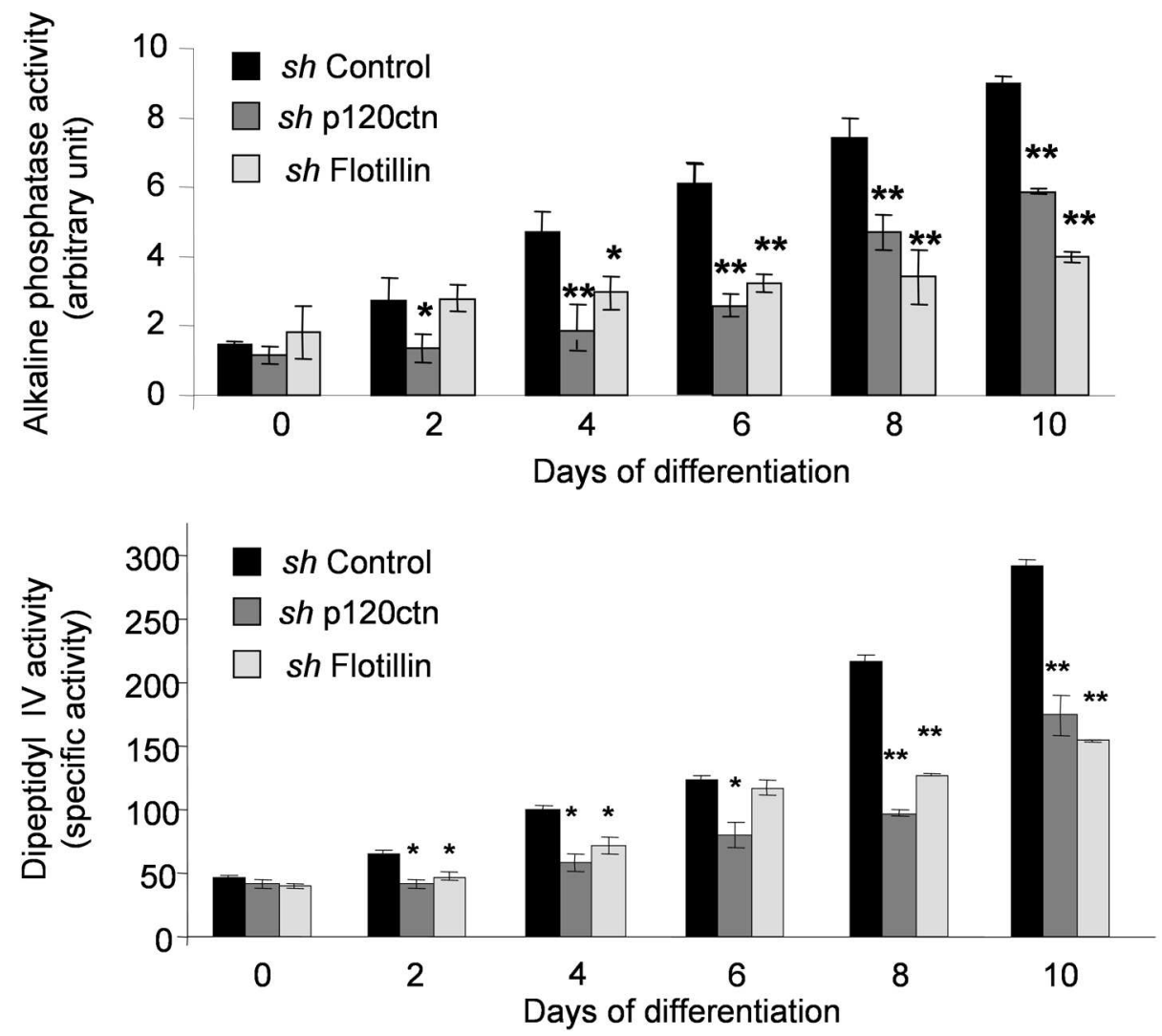

C

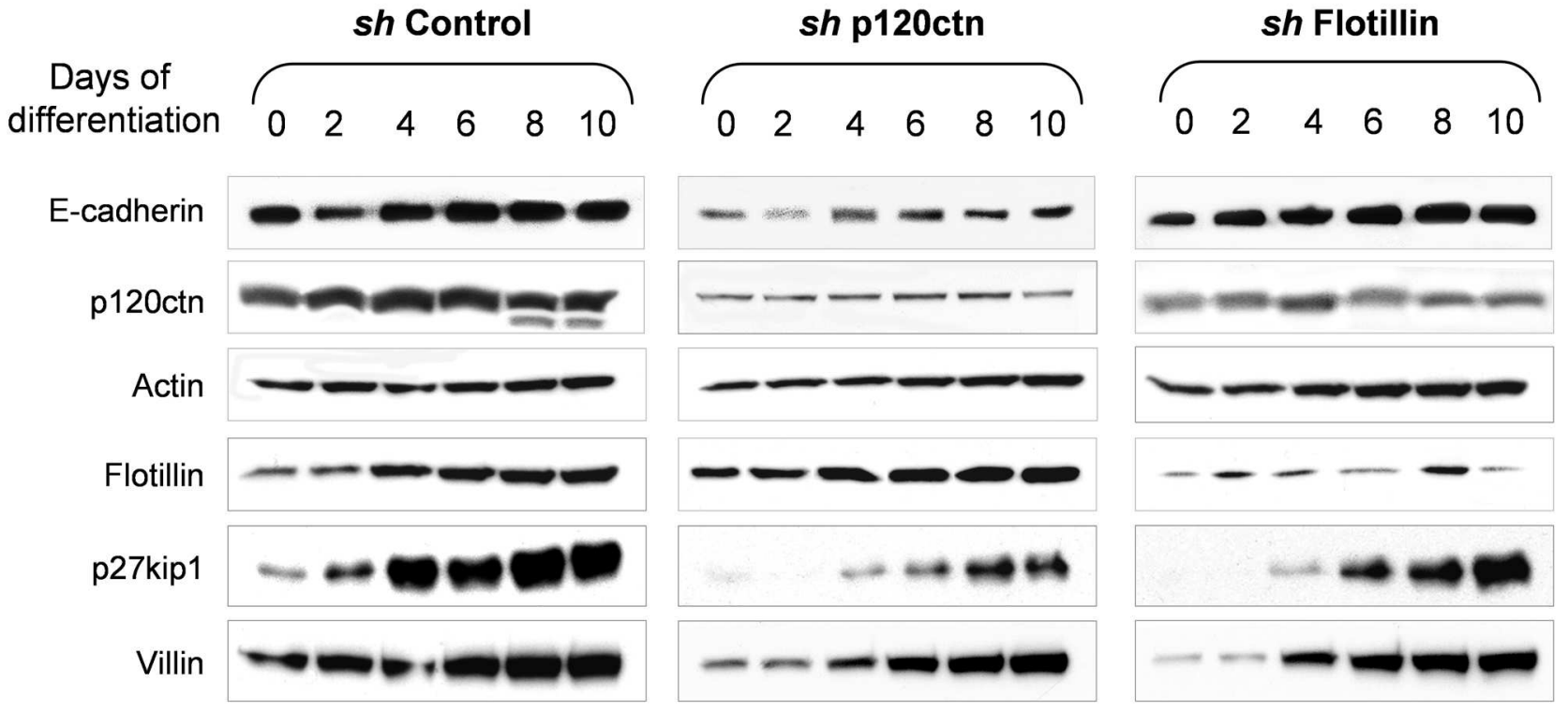


A

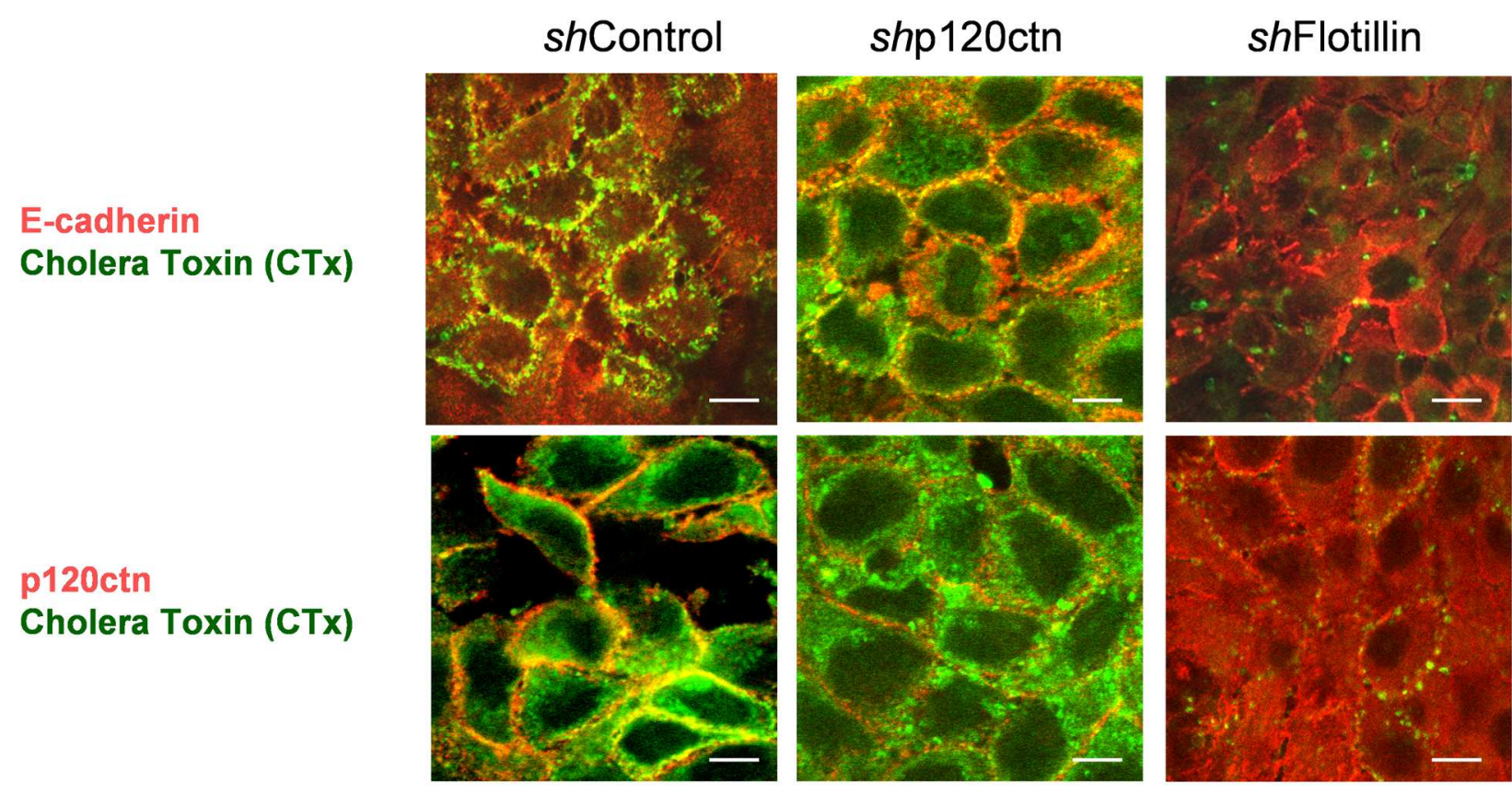

B

C
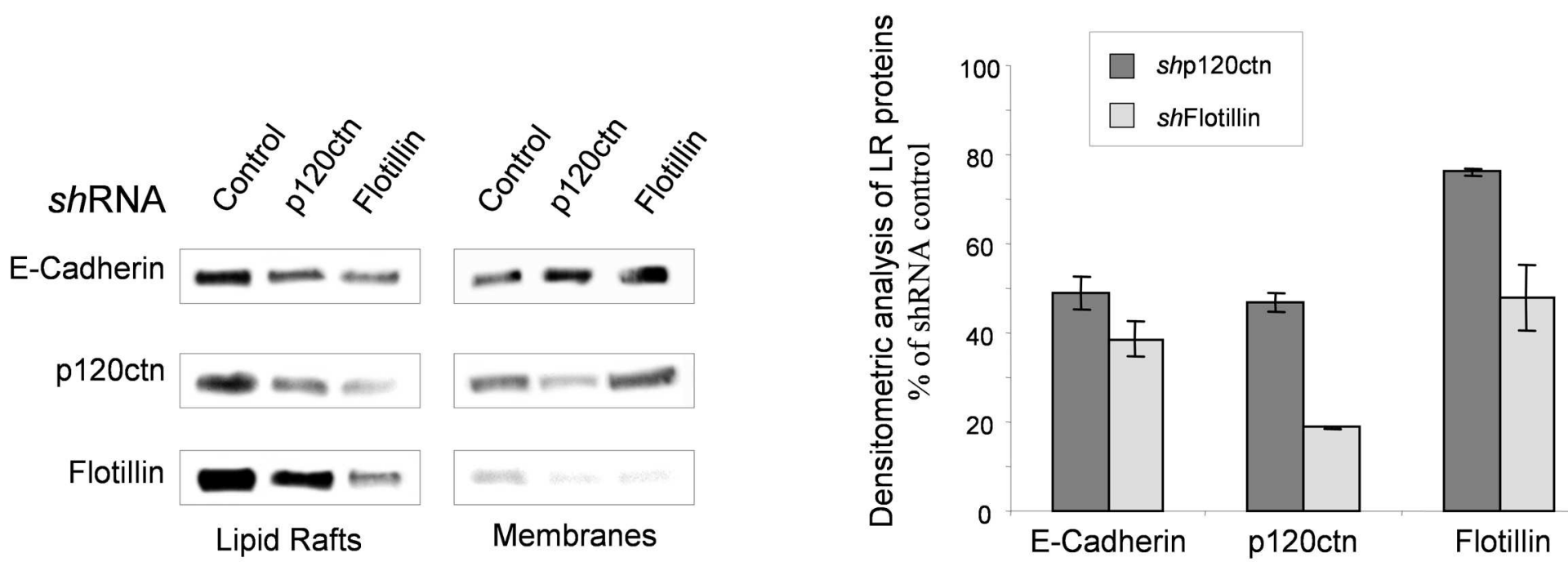

Figure 5 


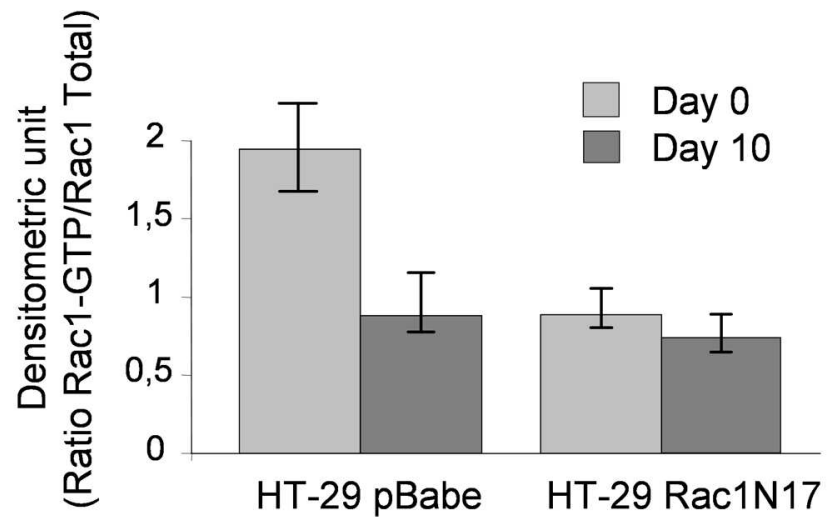

B
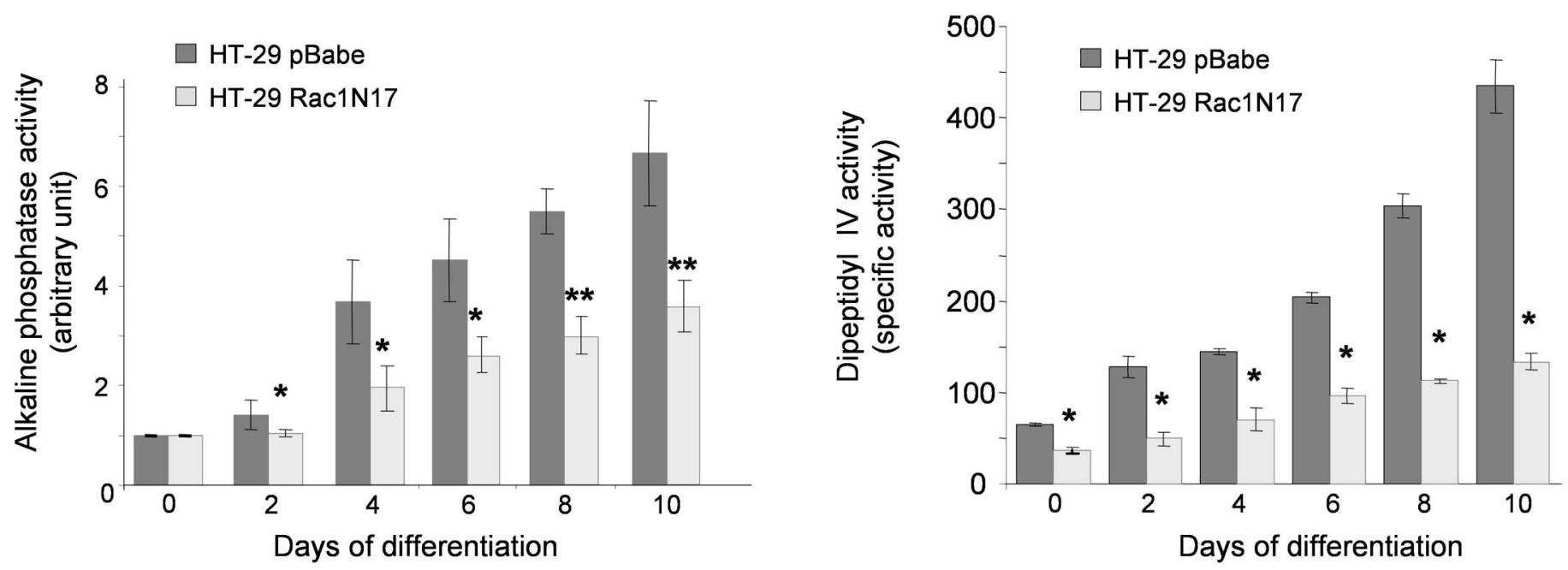

C

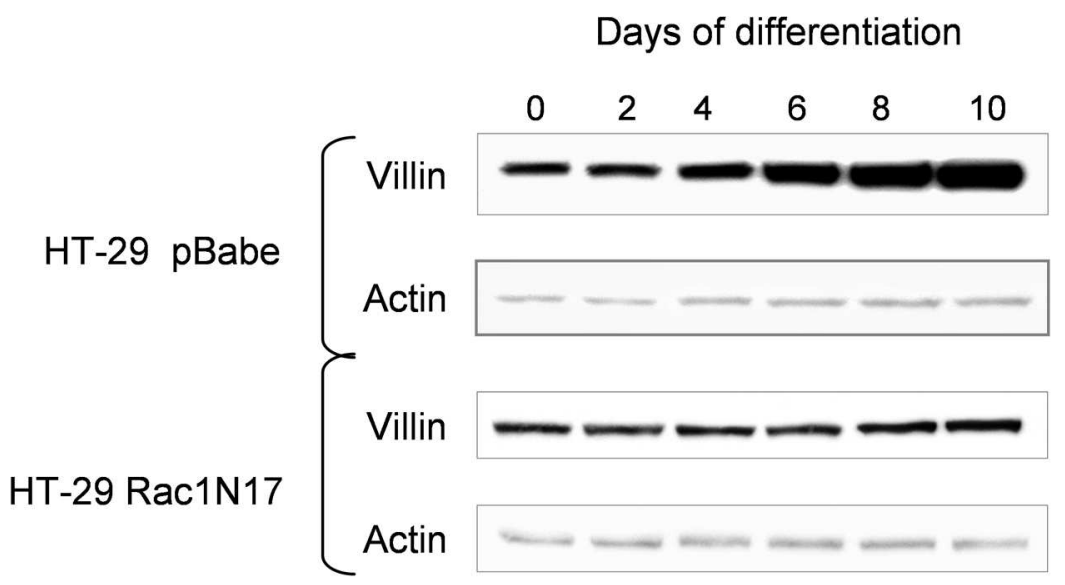

HT-29 pBabe

(Day 10)

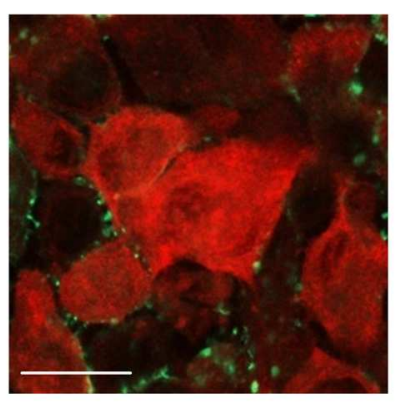

\section{HT-29 Rac1N17}

(Day 10)

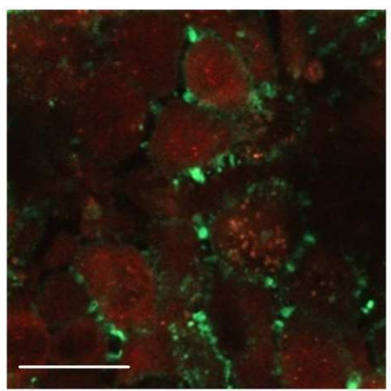

viiliin / CTx 
Days of
differentiation

E-cadherin

p120ctn

Flotillin

Actin
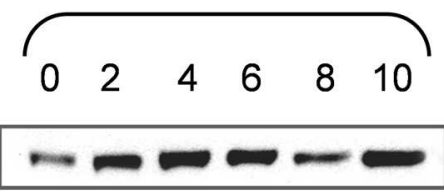

-m=0

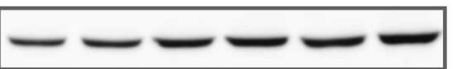

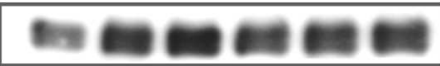
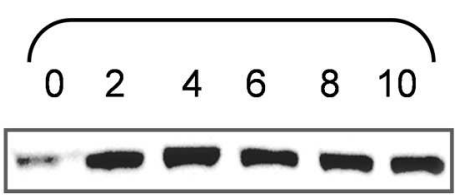

m 600

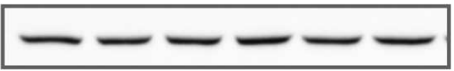

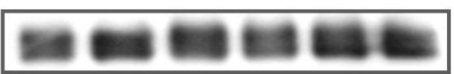

B HT-29 pBabe (Day 10)

E-cadherin

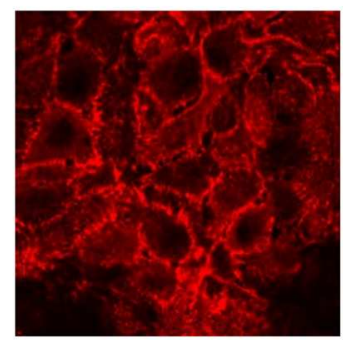

$\mathrm{CTX}$

Merge
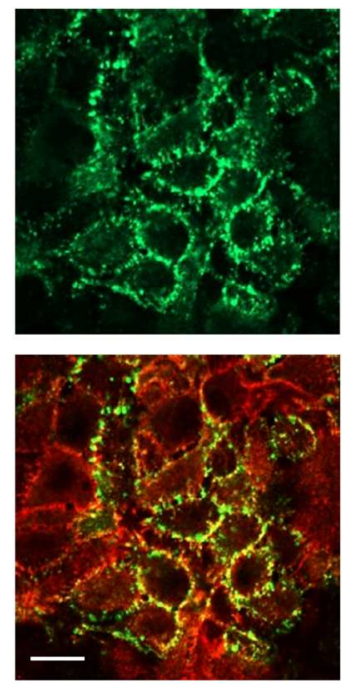

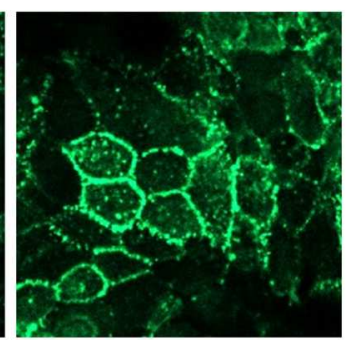

p120ctn
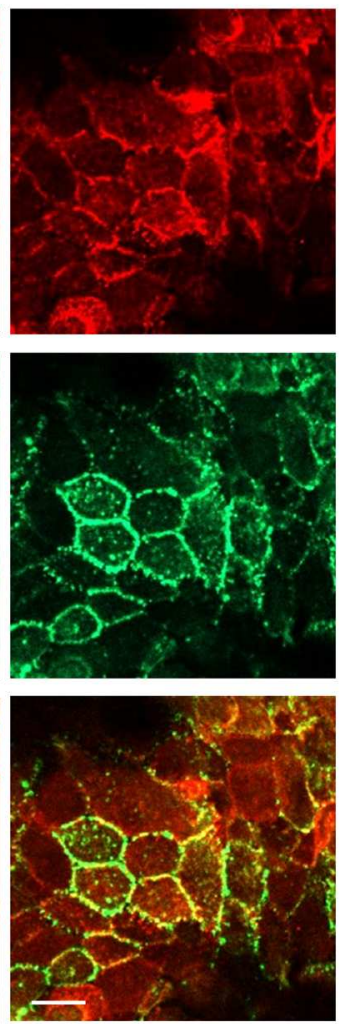

HT-29 Rac1N17 (Day 10)

E-cadherin
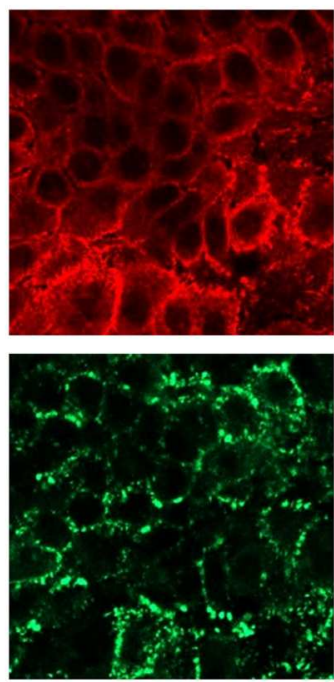

p120ctn
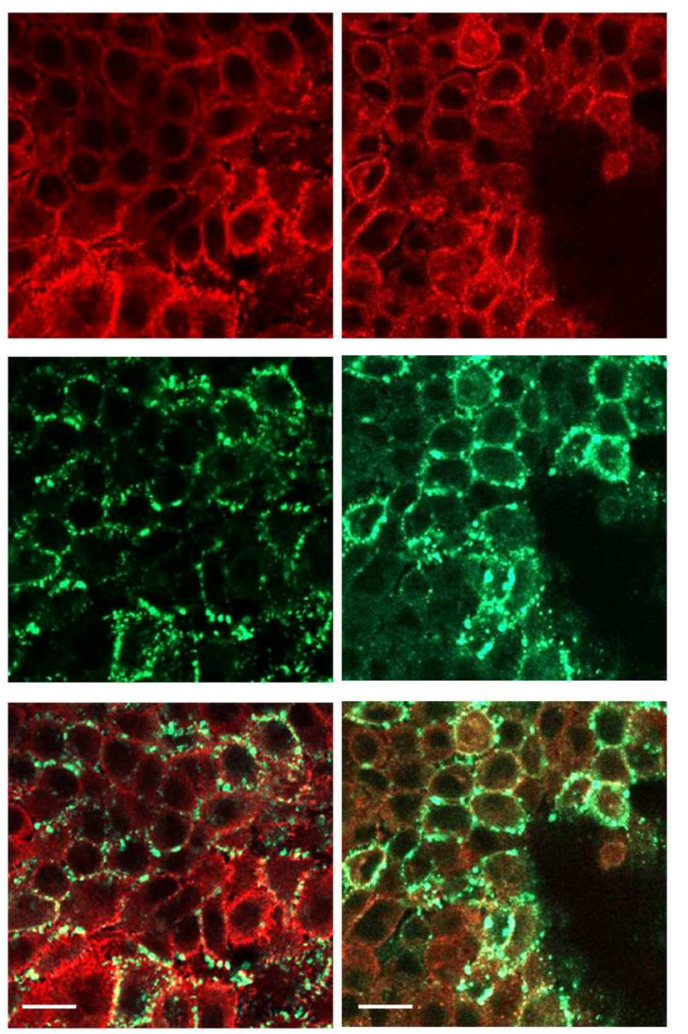

C

Gradient fraction $N^{\circ}$

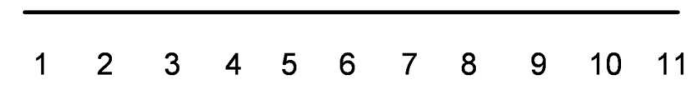

3

今
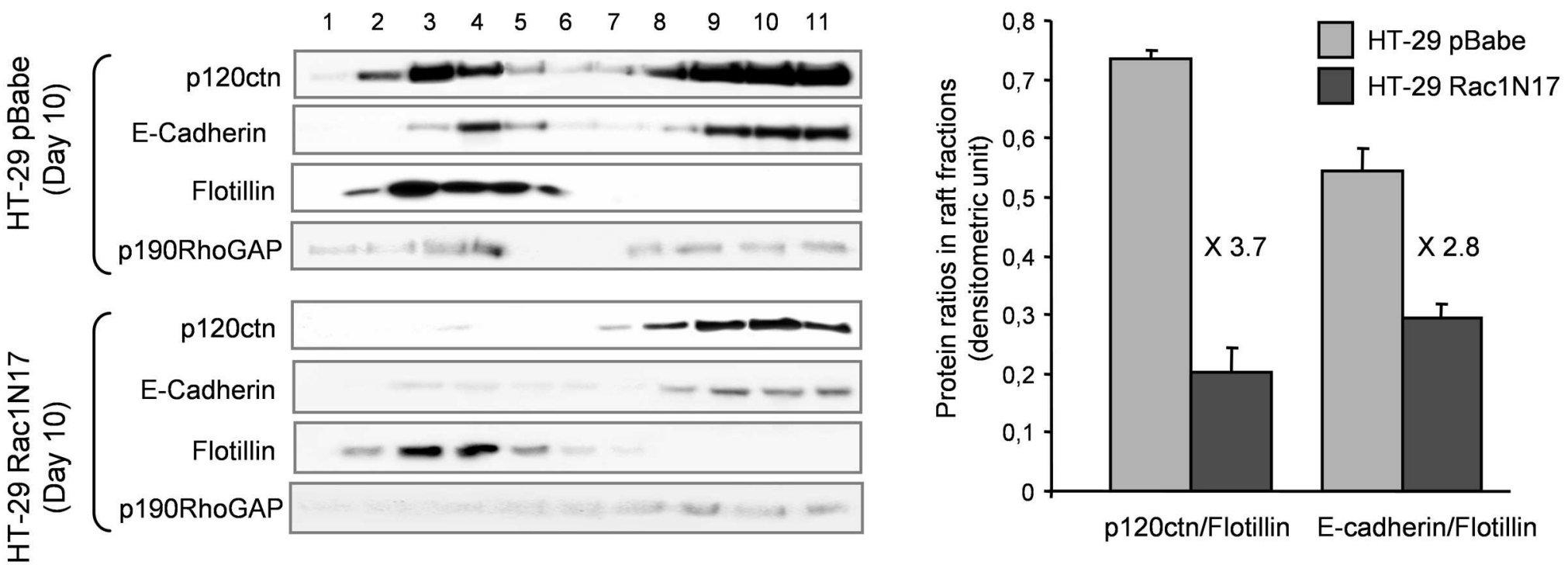

Figure 7 


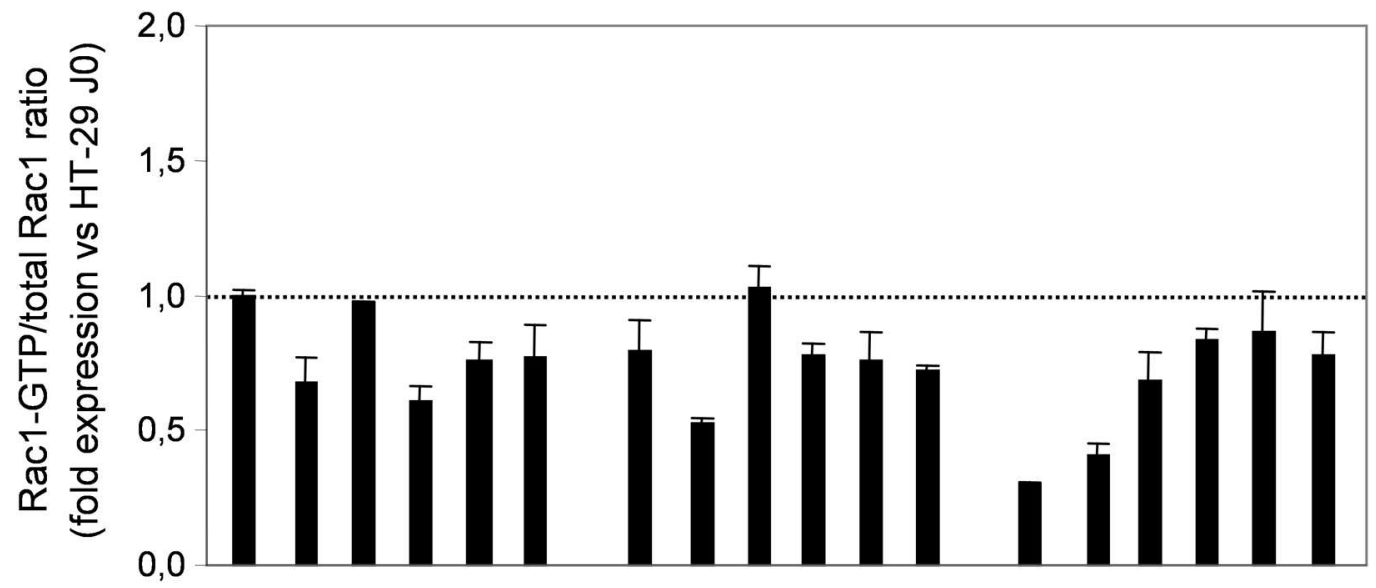

$\begin{array}{lllllllllllllllllll}\text { Days of differentiation } & 0 & 2 & 4 & 6 & 8 & 10 & 0 & 2 & 4 & 6 & 8 & 10 & 0 & 2 & 4 & 6 & 8 & 10\end{array}$
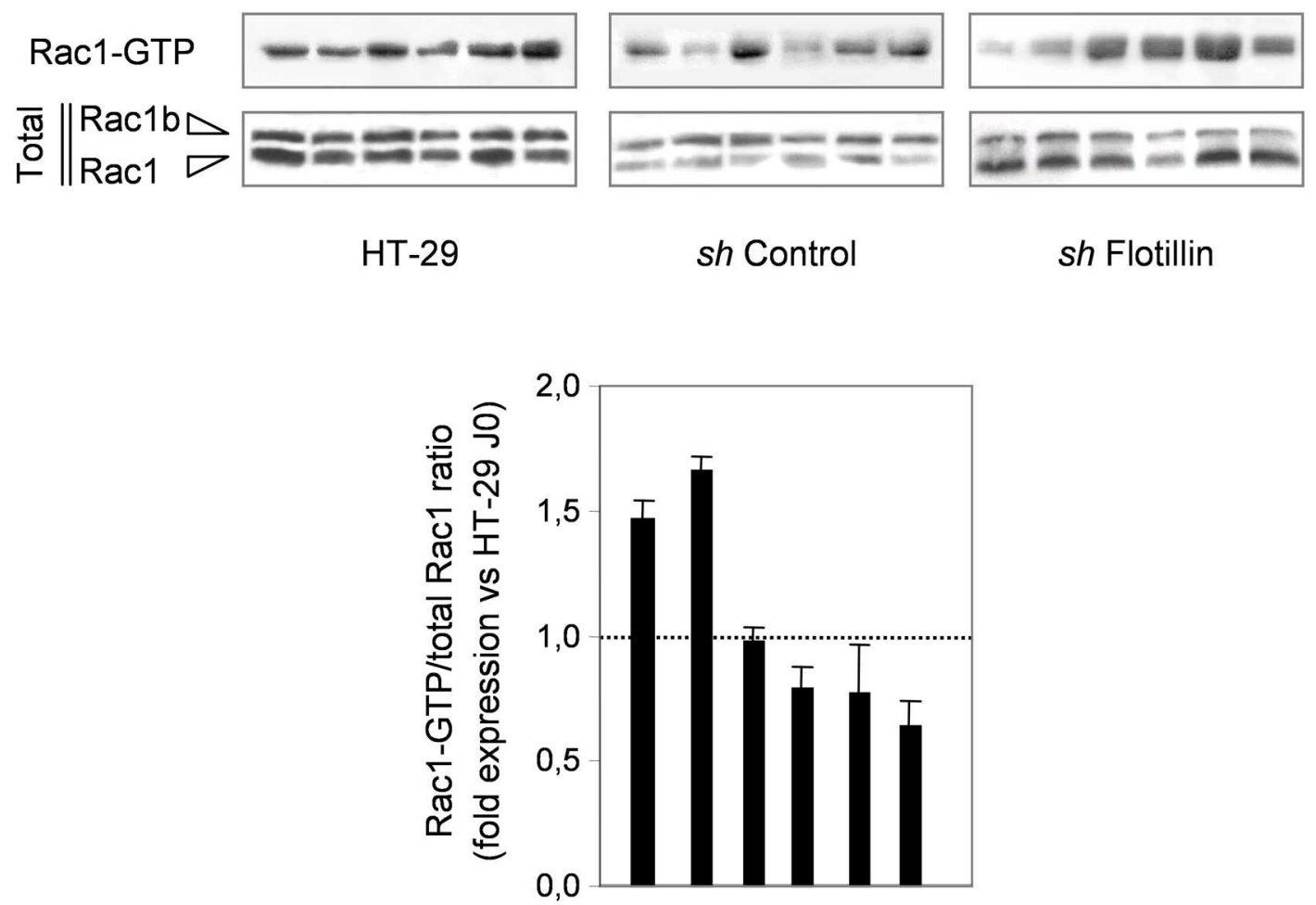

$\begin{array}{lllllll}\text { Days of differentiation } & 0 & 2 & 4 & 6 & 8 & 10\end{array}$

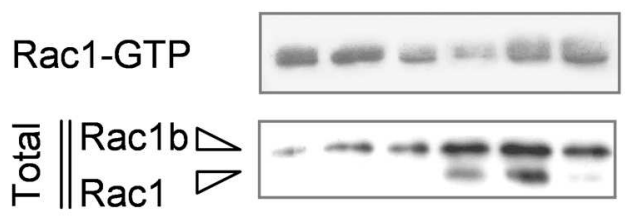

sh p120ctn

Figure 8 